\title{
COINCIDENCIAS ESTETTICO-LITERARIAS EN LA OBRA DE CICERÓN Y HORACIO
}

The new contributions this article makes arise, firstly, from the nature of its approach. The author does not restrict its scope to the collatio between a specific work by Cicero and another by Horace, as was customary, but reveals some aesthetic coincidences not appreciated to date. Secondly, the author, using as a base the aforesaid coincidences between Cicero and Horace, offers not only new interpretations on Horace's defined aesthetic criteria, but also an acknowledgement of some Horacian literary principles, which have not been previously thoroughly explained or even questioned by modern scholars.

\section{INTRODUCCIÓN}

"Aun cuando nos hayamos acostumbrado a observar la prosa y la poesía como dos procedimientos enfrentados», nos dice E. Norden, «no debiéramos olvidar que la diferencia entre ambas es básicamente de naturaleza secundaria y no principal»" '. Tal opinión, como señalaba M. Ruch ${ }^{2}$, ha sentado cátedra entre los filólogos clásicos. Éste es el caso de E. R. Curtius, quien afirma que «para los antiguos poesía y prosa no eran dos formas de expresión radical y esencialmente distintas» ${ }^{3}$.

I Die antike Kunstprosa, I, Stuttgart 1958, p. 30.

A. Fontán, "Tenuis Musa? La teoría de los xapartipes en la poesía augústea", EMERITA 32, 1964, pp. 193-208. El autor señala la mutua influencia entre prosa y poesía, destacando la adopción por parte de ésta de los genera dicendi de la oratoria, tal como lo había señalado Servio. A este respecto el autor señala que tal influencia no es aplicable todavía a los poetas augústeos.

${ }^{2} \mathrm{M}$. Ruch, "Horace et les fondaments de la iunctura dans l'ordre de la création poétique», $R E L$ 41, 1963, p. 246: "Hay la costumbre desde Norden de establecer un paralelismo entre la doctrina poética y la retórica». Frente a tal opinión señala J. Marouzeau (Quelques aspects de la formation du latin littéraire, París 1949, pp. 180-181) la profunda diferencia entre prosa y poesía, recordando cómo la poesía de las Sátiras de Horacio está plagada de formas familiares frente a la prosa literaria.

${ }^{3}$ E. R. Curtius, Literatura europea y Edad Media Latina, México 1955, p. 215. 
Dentro de tal interrelación viene siendo ya un lugar común atribuirle a Gorgias la plasmación de determinados principios poéticos en la prosa ${ }^{4}$. Recordemos, a este respecto, cómo en la antigüedad clásica $\mathrm{Ci}$ cerón responsabilizaba a aquél de haber trasladado los principios rítmicos a la prosa y cómo la opinión de Dionisio de Halicarnaso era del mismo tenor ${ }^{5}$. De igual modo, las manifestaciones de filólogos modernos interesados por la retórica clásica avalan el juicio de los antiguos. Este es el caso de K. Reich, quien, tras haber analizado la obra de Gorgias, señala: «Hay que concluir que Gorgias tomó sus figuras retóricas de la poesía" ${ }^{6}$. En términos semejantes se expresa G. Kennedy en el análisis que hace del sofista griego, al señalar que los rasgos comunes a la poesía, como son las antítesis, habían sido trasladados por aquél a la prosa ${ }^{7}$. No es, por lo tanto, extraño que ciertos procedimientos mágicos, más propios de la poesia, fueran trasladados, incluso, a la prosa $y$, concretamente, a la oratoria como uno de los recursos de la psychagogia ${ }^{8}$.

Cicerón se sumó, pues, a esta tradición representada por Gorgias de Leontino, Trasímaco Calcedonio, Teodoro de Bizancio, Isócrates, etc. ${ }^{9}$ En consecuencia nos recordará reiteradas veces el profundo parentesco existente entre el orador y el poeta ${ }^{10}$. De ahí que se considere legitimado para trasladar aspectos de la poética a la elocuencia ", prestándole

4 J. de Romilly, Magic and Rhetoric in Ancient Greece, Cambridge, Mass., 1975, p. 10. E. Rummel, "Isocrates' Ideal of Rhetoric: Criteria of Evaluation», $C J 75,1$, 1979, p. 29: «Gorgias introdujo por primera vez los elementos poéticos en la retórica».

S Or. 175: paria paribus adiuncta et similiter definita itemque contrariis relata contraria, quae sua sponte, etiam si id non agas, cadunt plerumque numerose, Gorgias primus inuenit, sed est usus intemperantius. Dion. de Halic., de imit. p. 31 Us.

6 K. Reich, Der Einfluss der griechischen Poesie auf Gorgias, der Begründer der Attischen Kunstprosa, Munich-Würzburg 1907-9, p. 57.

7 G. Kennedy, The Art of persuasion in Greece, Princeton 1963, p. 33.

8 M. G. Teijeiro, "Retórica, oratoria y magia», Estudios sobre el drama y retórica en Grecia y Roma, León 1988, pp. 143-153.

- Or. 39-41: Horum aetati successit Isocrates, qui praeter ceteros eiusdem generis laudatur semper a nobis non numquam, Brute, leniter et repugnante te. Nam cum concisus ei Thrasimacus minutis numeris uideretur et Gorgias... Theodorus autem praefractior nec satis... rotundus primus instituit dilatare... Itaque ut ego, cum a nostro Catone laudabar uel reprehendi me a ceteris facile patiebar, sic Isocrates uidetur testimonio Platonis aliorum iudicia debere contemnere.

${ }_{10}$ De or. I 70: Est enim finitimus oratori poeta. Ibidem III 27: quibus est proxima cognatio. De fin. I 10: Quando enim nobis, uel dicam, aut oratoribus bonis aut poetis... ullus orationis uel copiosae uel elegantis ornatus defuit?

"De or. III 174: Haec igitur duo uocis dico moderationem et uerborum conclusionem, quoad orationis seueritas pati posset, a poetica ad eloquentiam traducenda duxerunt. 
una atención inusitada al problema del numerus ${ }^{12}$ y de ahí que señale la necesidad de que el orador lea para su formación retórica a los poetas ${ }^{13}$. Más aún, el hecho de que considere el ornatus función común a la oratoria y poesía ${ }^{14}$ y el hecho de que denomine al arte retórico artificium bene dicendi, frente a la tradicional definición de ars suadendi, revela la nueva visión dada a la elocuencia, visión que trasciende el género oratorio para fundirse con la poesía. Tal interpretación sostenida por el Arpinate habría de encontrar clara confirmación en los tratados retóricos posteriores, al ilustrar aquéllos las figuras retóricas con ejemplos tomados de la poesía.

La presencia, por otra parte, de aspectos retóricos dentro del género poético es un hecho que, limitándonos al mundo romano, se remonta prácticamente a los orígenes de la literatura. En efecto, tanto la obra de Plauto como la de Terencio están entreveradas de procedimientos retó$\operatorname{ricos}^{15}$. De igual modo, en los tratados gramaticales, ocupados tanto en la descripción de la lengua latina para lograr la función del recte loqui como en el comentario de los poetas, vemos la creciente presencia de las figuras retóricas.

Pues bien, esta misma asociación entre prosa y poesía y, consiguientemente, entre retórica y poética aparece reconocida por el propio Horacio en distintas ocasiones, como ya han hecho ver M. A. Grant y G. C. Fiske ${ }^{16}$.

Así pues, sin negar la posible ascendencia que la obra de Filodemo y, más concretamente, los planteamientos poéticos de Neoptólemo de

12 Or. 226: Et quoniam plura de numerosa oratione diximus quam quisquam ante nos...

${ }^{13}$ De or. I 158: legendi enim poetae. Ibidem III 39: Sed omnis loquendi elegantia... augetur legendis oratoribus et poetis.

14 De fin. I 10: Quando enim nobis, uel dicam aut oratoribus aut poetis... ullus orationis uel copiae uel elegantis ornatus defuit?

is A. Fontán, "Cicerón y Horacio, críticos literarios", EC 72, 1974, pp. 186-216. E. Fränkel, Elementi plautini in Plauto, Florencia 1960, p. 339. A. Michel, "L'eloquenza romana", Introduzione allo Studio della Cultura Classica, Milán 1972, p. 552: "Ya Plauto se apasionaba con el virtuosismo de las figuras retóricas y de la palabra». G. Calboli, "La retorica preciceroniana e la politica a Roma", Eloquence et Rhétorique chez Cicéron, Fondation Hardt, Ginebra 1981, p. 53: «A propósito de la influencia de la retórica en Terencio... han sido considerados objeto de la misma los prólogos, pequeños discursos completos, en los que es posible hallar las figuras y tropos habituales e incluso una división de los mismos según los criterios señalados en la teoría retórica. El mismo Terencio presenta los propios prólogos como discursos". Cf. Heaut. 11: oratorem esse uoluit me, non prologum. Hec. 9: orator ad uos uenio ornatu prologi.

${ }^{16}$ M. A. Grant-G. C. Fiske, "Cicero's orator and Horace's Ars poetica", HSPh 35,1924, p. 4: «Es evidente que Horacio sintió ambas disciplinas como hermanadas, como se desprende de su discusión en Sat. I 4,38 ss., así como de su famoso resumen sobre las características estilisticas del sermon. 
Parion hayan podido ejercer sobre el Ars Poetica de Horacio ${ }^{17}$, es evidente que dicha obra está profundamente dominada por cuestiones retóricas. Por lo tanto, bien se quiera ver en dicho Ars la estructura formal de la literatura isagógica, como señala E. Norden ${ }^{18}$, bien se quiera ver en ella el esquema atribuido a Neoptólemo, como pretende entre otros C. O. Brink ${ }^{19}$ o bien "un bello desorden", como apunta De SaintDenis ${ }^{20} \mathrm{O}$, incluso, «el catecismo de una estética», como manifiesta $P$. Grimal $^{21}$, la verdad es que las grandes cuestiones planteadas en los tratados retóricos reaparecen en dicho Ars.

En consecuencia, si en la Quellenforschung horaciana no faltan estudios sobre la influencia filosófica de Cicerón en Horacio ${ }^{22}$, es lógico

Sat. I 4,39: Primum ego me illorum, dederim quibus esse poetas excerpam numero: neque enim concludere uersum dixeris esse satis.

Sat. I 10,11-13: sermone opus est modo tristi, saepe iocoso defendente uicem modo rhetoris atque poetae.

17 P. Boyancé, «A propos de l'Art poétique d'Horace», RPh 10, 1936, p. 20: «Tanto Rostagni como Immisch o Villeneuve concuerdan en admitir que Horacio debe a un crítico griego, Neoptólemo de Parion, no sólo, como nos indica su comentarista Porfirión, los consejos del Arte poética, sino también la sucesión en que los presenta». P. Händel, "Zur Ars poetica des Horaz", RhM 106, 1963, p. 186: "¿Por qué no citó entre sus lecturas a Neoptólemo de Pario? Sin duda influyeron sus preceptos, pero también está claro que tales preceptos se remontaban a las teorias griegas de los peripatéticos». F. Sbordone, "La poetica oraziana alla luce degli studi più recenti", $A N R W$ II $31,3,1981$, pp. 1866-1920. Este trabajo es una puesta al día sobre las distintas tesis habidas en relación con la estructura y ordenamiento de la obra y su relación con la de Neoptólemo.

18 E. Norden, "Die Composition und Litteraturgattung der horazischen Epistula ad Pisones», Hermes 40, 1905, p. 527: «Horacio se basó en los principios retóricos en virtud de la afinidad. No se basó en la Poética de Aristóteles porque le era desconocidan.

19 C. O. Brink, Horace on Poetry, Cambridge 1963. G. Williams, «Review and discussion", JSR 54, 1964, pp. 186-196. H. J. Mette, «Neoptolemos von Parion", RE XXXII, col. 2470: "Conviene tener en cuenta que Horacio siempre ha podido ampliar el sistema de Neoptólemo partiendo de otras fuentes".

${ }^{20}$ R. K. Hack, "The Doctrine of Literary Forms", HSPh 27, 1916, pp. 1-65. El autor señala (p. 4), basándose en la obra de Spingarn, History of Literary Criticism in the Renaissance, las críticas surgidas en el Renacimiento contra esta falta de unidad. E. de Saint-Denis, "La fantaisie et le coq-à-l'âne dans l'Art poétique», Latomus 22, 1963, p. 671: «Frente al estudio o arte rigida y fria el autor ha preferido el delectare informativo; frente al ars ha preferido el lenguaje desenfadado del sermo... Horacio ofrece una pintura grotesca de un monstruo con cabeza de mujer». Esta opinión fue contestada por L. Hartmann, "Les deux parties de l'Art poétique d'Horacel, Latomus 23, 1964, 506-10. La opinión de Saint-Denis es la misma que con anterioridad habian expresado Lehrs, Weissenfels, Kiessling, etc., para quienes el Ars Poetica era una "Form der Formlosigkeit". 436-447.

21 P. Grimal, "Horace: de l'art de vivre à l'art poétique», BAGB 23, 1964, pp.

${ }^{22}$ L. Alfonsi, «Orazio, epist. I 1,14», Latomus 21, 1962, p. 617: «El texto nullius addictus iurare in uerba magistri se corresponde con Tusc. IV 4,7... Esta muestra es 
que se produjeran iguales intentos para reconocer la ascendencia del Arpinate sobre el Venusino en este terreno de los principios estéticos desde el momento en que retórica y poética eran sentidas por ambos autores disciplinas afines ${ }^{23}$. En este sentido constituyen importantes hitos históricos las obras ya clásicas de G. Pierleoni, E. Norden, R. K. Hack y Grant-Fiske. G. Pierleoni en su artículo «L'Arte poetica di Orazio e il De oratore di Cicerone» $(A \& R$ 7-8, 1904, pp. 251-60) señala que «ambos escritos se presentan no muy desemejantes en el planteamiento general, en el desarrollo, en el fin e, incluso, en determinados aspectos». El autor establece, pues, el paralelismo entre las dos partes en que Craso divide su exposición (la primera concerniente a los fundamentos de la elocuencia y la segunda a la formación del orador) y las dos partes del Ars Poetica. Establece, igualmente, el paralelismo sobre la actitud preceptiva de Craso y Horacio, sobre la importancia social de uno y otro arte, etc.

E. Norden, al examinar en su artículo antes citado el Ars Poetica a la luz del arte retórico, la divide según criterios retóricos, diferenciando dos partes: la primera relacionada con el arte o técnica (techne) y la segunda con el artifex (technites). A la primera le adscribe las partes de la retórica (inuentio, dispositio, elocutio, etc.), a la segunda la formación del poeta, esto es, los officia poetae, el ideal de perfección, los medios de formación, etc.

Desde el momento en que E. Norden considera el Ars Poetica como un trasunto de los planteamientos desarrollados en los tratados técnicos $y$, concretamente, retóricos, y desde el momento en que no ve diferencia alguna entre el género en prosa y el poético, no es extraño que este autor vaya rastreando paralelismos $\mathrm{y}$, por lo tanto, vinculaciones teóricas entre el Ars horaciano y la retórica de Cicerón.

Dentro de este análisis comparativo es interesante el artículo de R. K. Hack, "The Doctrine of Literary Forms» (HSPh 27, 1916, pp. 165), quien, al reconocer que «la ocupación de Cicerón sobre la elocuencia guarda una correspondencia estrecha con aquélla de Horacio" (p. 7), pasa revista a tales coincidencias, fijándose singularmente en dos criterios de ascendencia platónica, soporte de toda concepción literaria, el concepto ideal de la obra de arte y el principio del decus.

una prueba de la influencia de Cicerón sobre Horacio y, especialmente, del Cicerón de las obras filosóficas». M. J. McGann, Studies in Horace's first book of Epistles, Bruselas 1969, p. 31: «La lectura del De officiis... fue el factor que, junto con su inclinación y experiencia, determinó básicamente el carácter filosófico del libron.

${ }^{23}$ R. K. Hack, o.c., p. 37: «El Ars poetica no es un fenómeno aislado. Está sombreada por una nube de testimonios entre los que destacan prioritariamente las obras retóricas de Cicerón". 
Por su parte M. A. Grant y G. C. Fiske presentaron dos grandes aportaciones sobre dicha vinculación. La primera es un largo articulo, "Cicero's Orator and Horace's Ars Poetica» (HSPh 35, 1924, pp. 1-74) y la segunda es el trabajo aparecido cinco años más tarde, Cicero's «De oratore" and Horace's "Ars Poetica» (Madison 1929). En relación con el primer estudio los autores señalan las coincidencias en objetivos (el Orator y el Ars tienen como objetivo una psychagogia) y procedimientos (ambas obras utilizan como hilo conductor el principio del decus), así como todos aquellos aspectos identificables en una y otra obra, tales como la fusión de filosofia y retórica o poesía, la división de los estilos literarios, etc. El segundo estudio pasa revista a todos y cada uno de los aspectos comunes al De oratore y Ars Poetica, siguiendo el método de la triple división de la obra en materia, arte y artifex.

Aun reconociendo la importancia que tales obras merecen para una valoración objetiva de la ascendencia ciceroniana sobre el Ars Poetica de Horacio, nuestro propósito, en esta ocasión, es observar no tanto la coincidencia puntual entre una obra determinada del Arpinate y dicho tratado horaciano, como viene siendo lo habitual, cuanto más bien la coincidencia de ambos autores en sus valoraciones estéticas. Tal objetivo no se limita, pues, al seguimiento detallado de aspectos estéticos observados en el Ars y en una obra retórica del Arpinate, sino que se plantea desde la constatación de coincidencias estético-literarias detectadas en la obra de Horacio al trasluz de la producción ciceroniana. No olvidemos, a este respecto, que los tratados retóricos de Cicerón, De oratore, Brutus y Orator integraban el corpus filosófico de su producción, como él mismo nos dice ${ }^{24}$, y que sus tratados propiamente filosóficos atendian ampliamente cuestiones de naturaleza estética ${ }^{25}$. Por otra parte, debemos tener presente que el Venusino no circunscribió sus opiniones literarias al Ars Poetica, sino que en otros muchos poemas suyos vertía igualmente sus opiniones literarias. En efecto, tanto la epístola a Augusto como la dedicada a Floro o aquella otra dedicada a Mecenas (I 19) atienden a cuestiones de naturaleza literaria, pudiendo decirse lo mismo de algunas Sátiras ${ }^{26}$.

24 De diu. II 4: Cumque Aristoteles itemque Theophrastus excellentes uiri cum subtilitate tum copia cum philosophia dicendi etiam praecepta coniunxerint, nostri quoque oratorii libri in eundem librorum numerum referendi uidentur.

2s A lo largo de nuestro estudio Cicerón ante la retórica, Valladolid 1987, hemos tenido ocasión de comprobar cómo las obras filosóficas del Arpinate y, especialmente, el tratado De officiis están cuajadas de consideraciones estéticas.

${ }_{26}$ O. Immisch, Horazens Epistel über die Dichtkunst, Leipzig 1932, p. 27. F. Sbordone, o.c., p. 1880: «Considerables ecos crítico-literarios figuran también en otras obras del Venusino. Se puede pensar en la Sat. I 4 con su típica exaltación del 
Como hilo conductor de tal collatio sobre principios estéticos hemos considerado oportuno distinguir, por un lado, la opinión de ambos autores sobre la figura del orador y poeta y, por otro, su concepto sobre la obra literaria, siguiendo precisamente el criterio señalado por $\mathrm{Ci}$ cerón: (Or. 61) sed iam illius perfecti oratoris et summae eloquentiae species exprimenda est. Con tal planteamiento se puede no sólo ahondar en la verificación de coincidencias estético-literarias, sino, además, reconocer el alto grado de conocimiento que Horacio tenía de la obra ciceroniana. Precisamente a lo largo de este estudio se podrá observar cómo la información que Horacio poseía de Cicerón no se limitaba a un tratado específico, sino que es reveladora de una profunda asimilación de los criterios estéticos de aquél.

\section{CONCEPCIÓN DEL ORADOR Y POETA}

Ya en el De oratore Craso, alter ego de Cicerón, defendía en su debate con Antonio la imagen del orador ideal, esto es, la idea del orator plenus et perfectus ${ }^{27}$, utilizando el término species para referirse a la idea objeto de imitación ${ }^{28}$. Nueve años más tarde el propio Arpinate desarrolla este mismo concepto del orador ideal sobre tales principios platónicos, como él mismo manifiesta ${ }^{29}$, señalando que su objetivo es contribuir a desarrollar aquella perfecti oratoris species (Or. 61).

Este mismo concepto del ideal perfecto sería recogido también por el propio Horacio en su Ars, pero referido en este caso al poeta ${ }^{30}$. Ambos autores partían, pues, de un planteamiento común de raíces platónicas. Ahora bien, tal concurrencia en la concepción ideal del orador y poeta no se agota en este supuesto estético. Precisamente en virtud de tal principio de perfección ideal Cicerón nos transmite a través de Antonio, el segundo personaje en importancia del De oratore, la opinión de que el público no le perdonaría a este tipo ideal de orador yerro al-

ingenium..." No se debe, por otra parte, ignorar que, como dice $M$. Lejay en la introducción a las Sátiras y Epístolas de su edición de Horacio, p. XL, «Horacio con el Ars poetica daba a su pensamiento la formulación definitiva».

${ }_{27}$ De or. I 59: sed oratorem plenum et perfectum esse eum, qui de omnibus rebus possit copiose uarieque dicere. Ibidem 85: Ac tamen, quoniam de oratore disputandum est, de summo oratore dicam.

2a De or. III 71: ... species oratoris perfecti. Cf. Or. 7.

29 Or. 101: Ego enim quod desiderem, non quid uiderim, disputo, redeoque ad illam Platonis... rei formam et speciem.

30 AP 372-3: ... mediocribus esse poetis

non homines, non di, non concessere columnae. 
guno, mientras, por el contrario, se mostraria mucho más indulgente con los representantes de otras artes ${ }^{31}$. Pues bien, esta misma opinión sobre la rigurosa exigencia, por un lado, y la condescendencia y comprensión, por otro, es trasladada por Horacio al poeta y a los representantes de otras artes respectivamente ${ }^{32}$. Horacio estaba utilizando la misma argumentación del Arpinate, pero aplicándola al poeta: así pues, el auditorio exigiría del poeta el cumplimiento del supuesto ideal, mientras sería mucho más comprensivo con los oradores cuyos yerros serían más perdonables.

En relación con todo ello, no podemos ignorar aquella tradición que, como se puede ver en Lucilio, reconocia la imperfección de autores considerados tradicionalmente como modélicos ${ }^{33}$. Es evidente que Lucilio se estaba haciendo eco en este caso de aquel ideario estético fijado por Calímaco, ideario éste que sería asumido por los poetae noui ${ }^{34}$. De ahi que, aun cuando Homero figurara como modelo de poesía y Demóstenes de elocuencia, no dejarían de ser acusados sus defectos desde tal credo literario.

Cicerón, al igual que otros autores, ejercerá la crítica contra Demóstenes, al reconocer las deficiencias de su obra. Ahora bien, dicha crítica respondia a las tesis del ideal platónico, no al planteamiento alejandrino ${ }^{35}$.

Horacio, por su parte, se halla incurso también en esta misma tradición de exigencia, por un lado, del poeta ideal y de reconocimiento, por

"De or. I 124-5: "Noluit", inquiunt, "hodie agere Roscius", aut, "crudior fuit"; oratoris peccatum, si quod est animaduersum, stultitiae uidetur; stultitia excusationem non habet.

32 AP 368-72: Tolle memor, certis medium et tolerabile rebus recte concedi; consultus iuris et actor causarum mediocris abest uirtute diserti Messalae nec scit quantum Cascelius Aulus, sed tamen in pretio est.

33 Luc. 345 (ed. Marx): ... nemo qui culpat Homerum

$$
\text { perpetuo culpat. }
$$

Lucilio, siguiendo una tradición escolar que establecía la distinción entre poesis y poema, señala que a Homero se le pueden reprochar algunos fallos, como determinados versos no logrados, pero nunca se le puede reprochar la poesis, esto es, el conjunto de la obra.

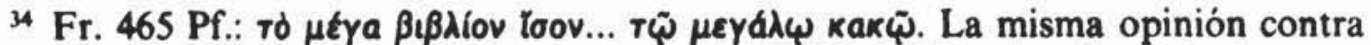
el gran poema aparece formulada en Catulo (XXXVI 1, 20): Annales Volusi, cacata charta. Es evidente la correspondencia entre el kaxóv calimaqueo y el cacata catuliano. Más aún, el hecho de que Catulo se estaba refiriendo al carmen continuum de Volusio aparece señalado en $V C$ 7-10.

${ }^{35}$ Or. 26: reprehendit Aeschines quaedam et exagitat illudensque dura, odiosa, intolerabilia esse dicit. (Or. 104) ut nobis non satisfaciat ipse Demosthenes. R. Pfeiffer, Historia de la Filología Clásica, Madrid 1981, p. 249. 
otro, de las deficiencias humanas. De todos modos, lo que llama poderosamente la atención sobre el grado de dependencia de Horacio con relación al Arpinate en esta cuestión es el hecho de que haya adoptado la misma formulación ciceroniana sobre la irritación que produce la comprobación del error en aquellos escritores modélicos. En efecto, la famosa sentencia horaciana (Ars 358-9: ... et idem / indignor quandoque bonus dormitat Homerus) es, como leemos en Quintiliano, un plagio ciceroniano: (Inst. X 1,29) cum Ciceroni dormitare interim Demosthenes, Horatio etiam Homerus uideatur. Esta misma opinión volverá a repetirla en su Institutio ${ }^{36}$. Evidentemente, Quintiliano, buen conocedor de la obra de ambos, no tenía motivos para falsear intencionadamente los hechos en aspectos, por otra parte, irrelevantes. En clara conexión con estos criterios se halla aquel desarrollo del concepto del orador ideal, esto es, de la species perfecti oratoris que leemos en Or. 7, donde Cicerón señala cómo es dificil, por no decir imposible, reconocer a este orador ideal en el conjunto de la obra (in perpetuitate dicendi) si bien se puede mostrar en algún momento de la misma (in aliqua autem parte eluceat aliquando) ${ }^{37}$. Un eco de tal opinión se detecta en Ars 348 ss.: Horacio señala igualmente la imposibilidad humana de lograr la perfección ideal, poniendo además en relación los posibles defectos de la obra con la extensión de la misma ( $A P$ 360: Verum operi longo fas est obrepere somnum).

Ambos autores, Cicerón y Horacio, estaban interpretando los criterios estéticos alejandrinos desde el idealismo platónico, esto es, reconocían, por una parte, la mayor dificultad de perfección en un carmen perpetuum u opus longum que en un fragmento, pero, por otra, afirmaban la superioridad del conjunto armónicamente estructurado frente a las partes, por muy bien cuidadas que estuvieran. Es revelador de esta misma valoración estética el hecho de que ambos autores hayan acudido al símil de la escultura para ilustrar tales principios literarios (Or. 234-6, AP 32-4).

No podemos olvidar, en este mismo orden de cosas, cómo la valoración de la superioridad del orador y poeta venía determinada en uno y otro autor por el dominio de lo sublime frente a lo vulgar. Si Cicerón

${ }^{36}$ Inst. XII 1, 22: quamquam neque ipsi Ciceroni Demosthenes uideatur satis esse perfectus, quem dormitare interim dicit.

${ }^{37}$ C. Monteleone, "Cicero, Orator 7", $R h M 116,1973$, pp. 60-9. Frente a la opinión de este autor que, siguiendo a W. Kroll, interpreta la expresión in perpetuitate dicendi como un periodo temporal, mi opinión se adhiere a la de Sandys y Yon, para quienes dicha expresión iba referida al conjunto de la obra: perpetuitate está refiriéndose al perpetuum opus. 
señalaba que el orador sólo podía alcanzar su consagración mediante el dominio de tal nivel oratorio ${ }^{38}$, Horacio distinguia igualmente el carácter sublime de sus carmina frente al nivel humilde de sus sermones ${ }^{39}$, consciente de que su inmortalidad le vendría otorgada por las Odas. Sólo, pues, a este género de hombres le estaba reservado el calificativo de sublimis, summus, diuinus, etc.

De igual modo se observa concurrencia de criterios en la identificación que ambos autores hacen del orador y poeta con el filósofo. Si el Arpinate establece tal identificación o, en otras palabras, si exige del orador su previa condición de filósofo (De or. III 142), en Horacio encontramos recogida la misma identificación entre el filósofo y el poeta, llegando a superar aquella tradicional dicotomía entre filosofia y poesía, esto es, entre res y uerba o ueritas y mendacia: prueba evidente de tal planteamiento es la Oda I 26 (Musis amicus...) en la que Horacio está identificando al poeta (Musis amicus) con el filósofo (sapientiae deditus), al atribuirle a aquél las características del filósofo, esto es, la independencia y libertad de espíritu.

El eco que las opiniones de Cicerón tuvieron sobre Horacio en este aspecto es, en nuestra opinión, evidente.

\section{NATURALEZA DIVINA DEL ORADOR Y POETA}

El planteamiento anteriormente observado enlaza con la naturaleza divina del orador y poeta reconocida, de manera similar, en Cicerón y

${ }^{38}$ Or. 96-7: Tertius est ille amplus, copiosus, grauis, ornatus, in quo profecto uis maxima est, hic est enim, cuius ornatum dicendi et copiam admiratae gentes eloquentiam in ciuitatibus plurimum ualere passae sunt. (99) At uero hic noster, quem principem ponimus...

${ }^{39}$ C. I 1, 36-7: quod si me lyricis uatibus inseres, sublimi feriam sidera uertice.

C. III 25, 17-20: Nil paruum aut humili modo nil mortale loquar. Dulce periculum est, o Lenaee, sequi deum cingentem uiridi tempora pampino.

Ep. II 1, 165: Et placuit sibi natura sublimis et acer

Ep. II 1, 250-1: ... nec sermones ego mallem repentes per humum.

AP 229: Migret in obscuras humili sermone tabernas.

H. Oppermann, «Das Göttliche im Spiegel der Dichtung des Horaz», Wege der Forschung, IC, 1972, p. 172: «El gran poema dedicado a Calíope, la cuarta Oda romana, III 4 (Descende caelo), expresa, al principio, el sentimiento de Horacio de haber sido llamado a ser poeta". H. J. Mette, "Genus tenue und mensa tenuis bei Horazn, Wege der Forschung, IC, 1972, pp. 220-4. No puedo suscribir, en consecuencia, la opinión de este autor, quien reduce la vida y producción literaria de Horacio al genus tenue, desconsiderando la diferente valoración del propio poeta sobre su obra, asi como el orgullo de sentirse poeta protegido por las musas. 
Horacio. En efecto, Cicerón nos presenta al orador como un ser divino, dotado de fuerza divina, al igual que lo haría Horacio con relación al poeta ${ }^{40}$. Más aún, el Arpinate asocia una vez más al orador y poeta confiriéndoles a ambos el don de la inspiración divina ${ }^{41}$.

Esta tesis ciceroniana tenía su fundamentación en la propia filosofia platónica ${ }^{42}$. Concretamente en el Fedro se puede ver a Sócrates transportado por un estado de entusiasmo divino al que se le denomina «locura de las musas» e igualmente en el Ión se habla del privilegio divino del poeta ${ }^{43}$. De ahí que Cicerón acepte el término furor para referirse a este arrebatamiento poético, tal como lo entendía Platón (De diu. I 80: quem si placet, appellet furorem dummodo is furor ita laudetur ut in Phaedro Platonis laudatus est). Desde este punto de vista Cicerón, por un lado, hace compatible el concepto del furor con el principio de la sabiduría exigida por los estoicos (Tusc. III 11: ut furor in sapientem cadere possit, non possit insania). Precisamente pocas líneas antes el Arpinate le había atribuido a Sócrates y estoicos la identificación entre insanos e insipientes (Tusc, III 10: ex quo intellegendum est eos qui haec rebus nomina posuerunt sensisse hoc idem quod a Socrate acceptum diligenter Stoici retinuerunt, omnis insipientes esse non sanos). Consiguientemente Cicerón se esforzará por marcar la diferencia entre furor e insania (Tusc. III 11: Hanc... insaniam, quae iuncta stultitia patet latius, a furore disiungimus).

Por otro lado, el Arpinate no es ajeno a la tradición que le atribuye a Demócrito el reconocimiento del auténtico poeta en virtud del arrebatamiento o mágica posesión ${ }^{44}$. De este modo intentaba compatibilizar

${ }^{40}$ De or. I 186: auctor tamen esse deus putatur, ut id ipsum quod erat hominis proprium, non partum per nos sed diuinitus ad nos esse delatum.

Sat. I 4, 43-5: Ingenium cui sit, cui mens diuinior atque os magna sonaturum, des nominis huius honorem.

41 Tusc. I 64: Mihi uero ne haec quidem notiora et illustriora carere ui diuina uidetur, ut ego aut poetam grauem plenumque carmen sine caelesti aliquo mentis instinctu putem fundere, aut eloquentiam sine maiore quadam ui fluere abundantem.

${ }^{42}$ P. Grimal, o.c., p. 439: «Su concepción de la poesía está muy próxima a la de Platón: el poeta es un espíritu divinon. A. Michel, Le Dialogue des orateurs de Tacite et la philosophie de Cicéron, París 1962, p. 137: «Se trata del entusiasmo, del noble delirio de las Musas, del que el filósofo hacía elogio en el Fedro». H. Funke, "Zur Ars poetica des Horaz», Hermes 104, 1976, p. 167: «Según Platón (Ion 536c) el poeta gracias a la fuerza divina está capacitado para dirigir las almas hacia donde quiera".

${ }_{43}^{43}$ Fedro $238 c ; 245$ a; Ión $536 c-d$.

4 De diu. I 80: negat enim sine furore Democritus quemquam poetam magnum esse posse. De or. II 194: Saepe audiui poetam tam bonum neminen - id quod a Democrito et Platone in scriptis relictum esse dicunt- sine inflammatione animorum exsistere posse. 
la sapientia exigida por la tradición estoica con el entusiasmo divino atribuido a Demócrito, basándose para ello en el propio Platón, como ya hemos visto (De diu. I 80).

En Horacio nos encontramos igualmente reflejada la asunción de esta tradición, así como la adscripción de la misma a Demócrito ${ }^{45}$. Incluso el lenguaje común utilizado por ambos autores, como furor, adflatus, insanus, etc., avala tal concurrencia de criterios. Es revelador de tal concurrencia la definición de ira como furor breuis observada en Horacio (Ep. I 6,62). Recordemos, a este propósito, cómo Cicerón distinguía ira de iracundia, definiendo el primer término como un estado accidental y, por lo tanto, transitorio frente al segundo, que era una predisposición natural y, en consecuencia, permanente, y cómo asociaba también los términos de ira y furor ${ }^{46}$. Más aún, Horacio no sólo se hace eco de la diferenciación semántica establecida por Cicerón entre insania y furor, sino que, al igual que aquél, le atribuía a los estoicos, en este caso, Crisipo, la identificación entre insania e insipientia o stultitia:

\section{Sat. II 3,43-5: quem mala stultitia et quemcumque inscitia ueri caecum agit, insanum Chrysippi porticus et grex autumat ${ }^{47}$.}

No es extraño, por otra parte, el que tal asociación entre stultitia e insania apareciera con mayor frecuencia en aquellas obras del Venusino más ligadas a la reflexión filosófica, como eran las Sátiras y las Epístolas (Sat. II 3,74; 159; 306; Ep. I 6,15). De ahí que el adverbio insanius (Sat. I 10,34) tenga el mismo significado que stultius.

\section{AP 296-7: Credit et excludit sanos Helicona poetas Democritus...}

H. L. Tracy, «Horace on the poetic afflatus", Latomus 35, 1975, pp. 408-12. A. Ortega, «El ingenio y la técnica al servicio de la poesía, según la mente de Horacion, Helmantica 2, 1951, pp. 184-94.

${ }^{46}$ Tusc. IV 27: In aliis iracundia dicitur, quae ab ira differt. Nat. deor. I 42: ira inflammatos et libidine furentis... Tusc. IV 77: quid est... quo non progrediatur eodem ira, quo furor... O. Heinze, Ciceronis Tusculanarum disputationum libri $V$. Stuttgart 1957, Coment. III 11, p. 10: «Quien es sabio no puede, según la doctrina estoica, caer en el estado del insipiens, insanus, pues la uirtus no se puede perder. Sin embargo el espíritu del sabio puede ser sacudido por el furom. Hor., Ep. I 2, 62: ira furor breuis est...

${ }^{47}$ M. Pohlenz, Die Stoa, Göttingen 1959, p. 153: «No es extraño que también los hombres como agrupación independiente se dividan en dos grupos, los sabios, que están en posesión del conocimiento y llevan una vida feliz, y los locos, que lastrados con el mayor mal, la ignorancia, no son capaces de realización alguna perfecta y viven en una profunda desdicha". 
Consiguientemente la calificación prestada por Horacio a los poetas como non sanos deberá ser entendida dentro de la tradición a la que el Arpinate ya había hecho referencia y, por tanto, deberá ser asociada más bien a aquel furor platónico, según la interpretación ciceroniana, que no a la insania en el sentido estoico.

Así pues, el Venusino exigirá del poeta el dominio de la sapientia y mostrará su rechazo hacia el poeta uesanus (Ars 445), asumiendo, como lo había hecho el Arpinate, una tradición en la que se asociaba el entusiasmo con la sapientia estoica sobre la auctoritas de Platón. Desde esta compatibilización de entusiasmo divino y sabiduría estoica se explica la actitud común de ambos autores frente al estoicismo contrario a los sentimientos.

Más aún, las exigencias de naturaleza estoica sobre la apatheia nunca les satisfarán plenamente, y de ahí la crítica común de ambos autores sobre el rigorismo estoico, esto es, sobre su insensibilidad e incomprensión hacia los problemas humanos ${ }^{48}$. Concretamente el matiz que el término humanus adquiere en Cicerón por la actitud inhumana del estoicismo es el mismo que recoge Horacio precisamente en las Sátiras. Cicerón había contrastado tal actitud intransigente con aquella otra defendida por académicos y peripatéticos, más comprensiva con las debilidades humanas y, consiguientemente, más humana. El Arpinate, al defender la tesis académica y peripatética, hacía explícita mención de sus fundadores, Platón y Aristóteles, contraponiéndolos claramente a aquellas otras dos figuras, Sócrates, interpretado por él con rasgos estoicos, y Zenón, el fundador de la escuela ${ }^{49}$. Desde estos planteamientos es lógico que estos dos autores, Cicerón y Horacio, consideraran legitimada la atención a las funciones del delectare y mouere animos, por oposición a los estoicos, vinculados tan sólo a la disputandi ratio, esto es, a la función del docere o probare.

Concretamente una prueba más de esta comunión de criterios estéticos entre ambos autores se observa en el planteamiento que uno y otro hacen sobre la necesidad de estar entusiasmado para entusiasmar. Horacio no sólo estaba trasladando a la poesía el recurso retórico del pa-

48 Cicerón afirma el concepto de humanus frente al carácter inhumanus en que el rigorismo estoico había caido, como se puede ver en Mur. 62 ss., Lael. 50, De off. III 98, etc. Horacio, de igual modo, se dirige contra este estoicismo extremo con cierta ironia, como muy bien señala M. Pohlenz (o.c., p. 156) y se puede comprobar en Sat. I 3, 115, Ep. I 1, 108 y AP 101-2.

49 Mr. 61: Huius (sc. Zenonis) sententiae sunt et praecepta eiusmodi, sapientem gratia numquam moueri... (63) Nostri autem illi... a Platone et Aristotele, moderati homines et temperati, aiunt apud sapientem ualere aliquando gratiam. 
thos, al identificar tal procedimiento con el arrebatamiento y entusiasmo, como ya lo hiciera Cicerón, sino que además estaba asumiendo aquella opinión expresada por el Arpinate sobre la necesidad de emocionar por medio de la propia emoción ${ }^{50}$. Desde este punto de vista de aceptación de los sentimientos con cierta concesión a ese furor platónico, tal como lo entendía Cicerón, es como se entienden aquellas manifestaciones horacianas sobre su propia emoción poética: éste es el caso del dulce mihi furere est (C. II 7,28), dulce est desipere in loco (C. IV 12,28 ) o bien del insanire iuuat (C. III 19,18), donde el eco virgiliano se hace evidente ( $B$. III 36 ).

En definitiva, la concepción divina del orador y poeta asumida por uno y otro integraba la exigencia estoica de la sapientia con el furor o entusiasmo divino en sentido platónico: de este modo ambos autores rechazarán al enajenado igual que al necio, al identificar desde supuestos estoicos a estas dos figuras. Desde este planteamiento ambos autores están superando, por un lado, aquella visión del poeta como hombre dominado exclusivamente por fuerzas irracionales - delirans, uesanus - y, por otro, se oponen, desde la libertad que les caracteriza frente a cualquier secta filosófica, a aquella negación del mundo de la sensibilidad y sentimiento, tal como lo pretendian los estoicos: de ahí la aceptación del furor platónico por parte de Cicerón y de ahí el dulce furere horaciano.

\section{IMPORTANCIA DEL INGENIVM}

Desde esta interpretación de la naturaleza divina del orador y poeta es lógico que fuera cuestionada la utilidad de las artes retóricas o poéticas. Ya en el Gorgias y en el Fedro platónicos nos encontramos planteada esta quaestio ${ }^{31}$. Cicerón, por su parte, nos informa en el De oratore I 84 ss. sobre las diferentes opiniones de los escritores griegos en rela-

${ }^{50}$ De or. II 189: Neque fieri potest ut doleat is qui audit... nisi omnes illi motus, quos orator uolet iudici, in ipso oratore impressi esse atque inusti uidebuntur.

AP 102-3: ... si uis me flere, dolendum est primum ipsi tibi.

N. Rudd, "The Style and the man", Phoenix 18, 1964, p. 220: "Cicerón, Horacio y Quintiliano están de acuerdo en señalar que el mejor medio para hacer un estilo persuasivo es sentir uno mismo las emociones".

s1 Gorg. 462 b; Fedro 262 d. B. Wiśniewski, "Gorgias, Hippias et le de oratore», Prometheus 5, 1980, pp. 248-58. Este autor establece-1a distinción entre physis y theia moira, esto es, entre la capacidad natural y la inspiración divina, distinción que en Cicerón no tiene cabida. 
ción con la necesidad o no del arte retórico ${ }^{52}$. Sería, según el testimonio del propio Arpinate ${ }^{53}$, desde la vertiente filosófica desde la que este género de artes contaría con menos adeptos. El propio Craso, portavoz de Cicerón en el De oratore, al intervenir en el debate, plantea el asunto en el nivel de una quaestio definitiua: (De or. I 107) sed omnem esse contentionem inter homines doctos in uerbi controuersia positam. La vida del propio Cicerón es, en este sentido, un claro ejemplo de tal división de opiniones. Concretamente en su obra de juventud, el tratado De inuentione, reconocerá la utilidad de dicho arte ${ }^{54}$, alineándose en aquella misma tradición en la que se hallaba la Rhetorica ad Herennium: (I 3) Haec omnia tribus rebus adsequi poterimus: arte, imitatione, exercitatione. De igual modo Antonio, miembro también del diálogo De oratore, designado precisamente como artifex, asume el papel de preceptor ${ }^{55}$, y de ahí que frente a Craso defienda la utilidad de dicho arte ${ }^{56}$. Craso, en cambio, representante de la opinión ciceroniana, que no era otra sino la filosófica, exige como condición imprescindible para alcanzar el nivel oratorio deseado el principio de la natura o ingenium amén del studium y doctrina ${ }^{57}$. En consecuencia, presenta como objeción a la opinión de Antonio el argumento de que si fuera posible alcanzar la elocuencia a través del arte habría más oradores, cosa, nos dice Craso, que no ocurre $^{58}$. De ahí las dos sentencias ciceronianas reveladoras de tal sentimiento sobre la oposición entre ingenium y ars: (De or. I 146) sic esse

52 A. Alberte, Cicerón ante la retórica, "Actitud de Cicerón ante la figura del rétor y la retórica», Valladolid 1987.

${ }_{53}$ De or. I 83: Mnesarchus, hos, quos nos oratores uocaremus, nihil esse dicebat nisi quosdam operarios lingua celeri et exercitata; oratorem autem, nisi qui sapiens esset, esse neminem. (84) Chamadas uero... hoc significabat, eos, qui rhetores nominarentur et qui dicendi praecepta traderent, nihil plane tenere neque posse quemquam facultatem adsequi dicendi, nisi qui philosophorum inuenta didicisset. Disputabant contra diserti homines Athenienses et in re publica causisque uersati, in quis erat etiam is... Menedemus. (109-110) Tum Antonius... se adsentiri Crasso dixit, quod neque ita amplecteretur artem, ut ei solerent, qui omnem uim dicendi in arte ponerent, neque rursus eam totam, sicut plerique philosophi facerent, repudiaret.

s4 De inu. I 4: hoc si forte non natura modo, neque exercitatione conficietur, uerum etiam artificio quodam comparatur, non alienum est uidere, quae dicunt ii qui quaedam eius rei praecepta nobis reliquerunt.

"A. Alberte, "Idealismo y pragmatismo en el tratado ciceroniano De oratore", EC 88, 1984, pp. 303-310.

${ }^{36}$ De or. II 32: Vt igitur de ipso genere sum confectus, inquit Antonius, artem esse non maximam, sic illud adfirmo, praecepta posse quaedam dari peracuta ad pertractandos animos hominum et ad excipiendas eorum uoluntates.

57 De or. I 113: Sic igitur, inquit, sentio, Crassus, naturam atque ingenium ad dicendum uim adferre maximam, neque uero istis, de quibus paulo ante dixit Antonius, scriptoribus artis rationem dicendi et uiam, sed naturam defuisse.

s8 De or. II 232: quae si eloquentes facere possit, quis esset non eloquens? 
non eloquentiam ex artificio, sed artificium ex eloquentia; (De or. I 110) nihil decet inuita Minerua, id est, aduersante et repugnante natura.

La primera señala el carácter secundario que genéticamente le corresponde al ars frente al ingenium, auténtico artífice de la obra literaria. La segunda muestra metonimicamente la imposibilidad de conseguir objetivo alguno sin las dotes naturales requeridas.

Horacio, al igual que Cicerón, hace referencia a la historia de esta vieja querella ${ }^{59}$, planteando también en términos de una quaestio retórica dicha polémica $y$, al igual que aquél, señala la necesidad del ingenium, studium y doctrina o sapientia ${ }^{60}$, sirviéndose de aquella triple condición que Cicerón había tomado del Fedro platónico ${ }^{61}$. Horacio, en definitiva, exigirá, además del labor limae, la uis y la doctrina para aproximarse al poeta ideal. Tal grado de dependencia se hace palmario al comprobarse que Horacio utiliza aquellas mismas figuras literarias que había empleado Cicerón. Éste es el caso, en primer lugar, de la misma metonimia empleada también por el Arpinate: (AP 385) Tu nihil inuita dices faciesue Minerua ${ }^{62}$. En segundo lugar, se puede observar cómo Horacio utiliza aquel mismo símil empleado por el Arpinate para referirse a la integración del ingenium y doctrina ${ }^{63}$.

Dentro de este orden de coincidencias se puede ver cómo ambos autores manifiestan con toda claridad la necesidad de que el orador y el poeta deberán adecuar la obra a su propia capacidad, debiendo, por tanto, conocer previamente sus facultades, esto es, su ingenium o natura: (Off. I 113) Id enim maxime quemque decet, quod est cuiusque maxime. Suum quisque igitur noscat ingenium.

\section{AP 38-40: Sumite materiam uestris, qui scribitis, aequam uiribus et uersate diu quid ferre recusent, quid ualeant umeri.}

Ep. II 1,157-9: ... sed neque paruum carmen maiestas recipit tua, nec meus audet rem temptare pudor quem uires recusent.

\footnotetext{
39 AP 408-9: natura fieret laudabile carmen an arte quaesitum est.

60 AP 309: Scribendi recte sapere est principium et fons.

AP 409-10: ... ego studium sine diuite uena

${ }^{61}$ Fedro 269 c. nec rude quid possit uideo ingenium.

${ }^{62}$ Grant-Fiske, o.c., p. 48.

${ }^{63}$ Tusc. II 13: Vt ager quamuis fertilis sine cultura fructuosus esse non potest, sic sine doctrina animus

C. IV 4,33-4: doctrina sed uim promouet insitam rectique cultus pectora roborant.
} 
El grado de coincidencias en este aspecto concreto se hace evidente, una vez más, cuando observamos que la humanitas de Cicerón de reconocer el derecho a iniciarse en empresas literarias a quien no está capacitado para obtener el primer rango se halla recogido sentenciosamente por Horacio: (Or. 4) prima enim sequentem honestum est in secundis tertiisque consistere; (Ep. I 1,32) Est quadam prodire tenus, si non datur ultra.

En definitiva, ambos autores superan la tradicional oposición entre ars e ingenium, asumiendo el punto de vista expresado en el Fedro platónico, esto es, la necesidad de que tanto el orador como el poeta deben poseer no sólo el ingenium sino también la doctrina y el labos.

\section{FORMACIÓN FILOSÓFICA DEL ORADOR Y POETA}

Así pues, ni para Cicerón ni para Horacio la natura por sí sola era suficiente para alcanzar el grado de perfección deseado en el orador y poeta. Ambos demandaban la necesidad de la doctrina.

En efecto, para Cicerón la filosofia en cuanto constituye el mejor camino hacia la sapientia y, por lo tanto, hacia el dominio de la res, era principio previo e imprescindible para cualquier proyecto literario ${ }^{64}$. Cicerón, precisamente en conexión con la formulación catoniana del rem tene uerba sequentur ${ }^{65}$, hará hincapié en este dominio de la res como presupuesto indispensable para la formación del orador y así, en frase de corte catoniano nos dice: (De or. III 125) rerum enim copia uerborum copiam gignit $^{66}$. Esta idea la vemos repetida en sus tratados filosóficos (De fin. III 52: re... intellecta in uerborum usu faciles esse debemus) y significativamente puesta en boca de Catón de Útica, biznieto de Catón el Censor: se trata de aquel Catón del que nos dice en Parad. 1: Catonem... locos tractare abhorrentes ab usu forensi et publico, y al que denominará, pocas líneas después, Cato autem perfectus Stoicus, como lo hace también en el Brut. 118.

Tal formación parecía, pues, entroncarse con aquella vieja tradición representada por los estoicos, para quienes el objetivo literario consistía

64 Or. 70: Sed est eloquentiae sicut reliquarum rerum fundamentum sapientia.

6s Iul. Vict., Rhet. I 374: Scire autem est rem, de qua dicturus sis, uniuersam ante pernoscere (in hanc rem constat etiam Catonis praeceptum paene diuinum, qui ait: rem tene, uerba sequentur).

of De or. I 19-20: Ac mea quidem sententia nemo poterit esse omni laude cumulatus orator, nisis erit omnium rerum magnarum atque artium scientiam consecutus: etenim ex rerum cognitione efflorescat et redundet oportet oratio. Ibid. II 146: Ea ui sua parient, quae semper satis ornata mihi quidem uideri solent, si eius modi sunt, ut ea res ipsa peperisse uideatur. 
única y exclusivamente en el dominio de la res, de la sapientia con total desconsideración del ornatus. Ahora bien, Cicerón, aun cuando reconoce como premisa inexcusable la formación filosófica, no dejará de demandar como complemento igualmente ineludible la debida atención al ornatus. Para éste la elocuencia no es, por lo tanto, una consecuencia natural de la formación filosófica, tal como lo pretendian los estoicos, sino el resultado de la atención debida no sólo al contenido sino también a la expresión formal ${ }^{67}$. Consiguientemente el Arpinate les reprochará a los estoicos su falta de sensibilidad literaria calificando su producción con términos negativos ${ }^{68}$. De ahí la descalificación literaria que hace de aquellos romanos comprometidos con dicha escuela. Éste era el caso de L. Elio, del que nos dice que había antepuesto su estoicismo a la elocuencia ${ }^{69} \mathrm{o}$ de Catón de Útica, representante perfecto del estoicismo, como ya hemos señalado ${ }^{70}$, o de Fanio y Escauro, oyentes de $\mathrm{Pa}$ necio ${ }^{71}$.

Precisamente esta vinculación exclusiva a la res con total desaferto hacia el ornato, esta búsqueda exclusiva de la sabiduría con absoluto desprecio hacia la elocuencia es la misma que Cicerón le atribuye a Sócrates, aquel hombre caracterizado por la inscientia dicendi ${ }^{72}$. Cicerón le reprochaba a éste no sólo el discidium linguae et cordis $^{73}$, sino también su desconsideración hacia el aspecto formal ${ }^{74}$.

${ }^{67}$ A. Alberte, Cicerón ante la retórica, «Exigencia de la formación filosófica del orador", Valladolid 1987.

"s A. Alberte, Cicerón.... "Aspectos formales de la retórica ciceroniana». En este capítulo pasamos revista a las descalificaciones que Cicerón dirige contra los estoicos y hace extensivas a los aticistas. Cf. De fin. IV 78: (sc. Stoici) horridiores euadunt, asperiores, duriores et oratione et moribus... nec fuit.

fort. Brut. 206: Sed idem Aelius Stoicus esse uoluit, orator autem nec studuit umquam

ro Parad. 2: Cato, perfectus mea sententia Stoicus, et in ea sentit, quae non sane probantur in uulgus et in ea est haeresi quae nullum sequitur florem orationis...

"Brut. 101: C. Fannius... et moribus et ipso genere dicendi durior... Is instituto Laeli Panaetium audiuerat... (114) Scaurus... Panaetii auditor, prope perfectus in
Stoicis... sunt eius orationes ieiunae.

72 De or. I 233: (sc. Socrates) cum ille damnatus nullam aliam ob culpam nisi propter dicendi inscientiam.

${ }^{73}$ De or. III 60: Hoc commune nomen eripuit sapienterque sentiendi et ornate dicendi sapientiam re cohaerentis disputationibus suis separauit. Hinc discidium illud ex-
stitit quasi linguae et cordis...

74 De or. I 63: Atque illud est probabilius, neque tamen uerum, quod Socrates dicere solebat, omnis in eo quod scirent satis esse eloquentis. Illud verius neque quemquam ac poliendae orationis, diserte id nesciat neque si optime sciat ignarusque sit faciundae ac poliendae orationis, diserte id ipsum, de quo sciat, posse dicere. Esta misma opinión seria reiterada por Quintiliano y Julio Victor. Quint., II 21, 4: Socrates apud Platonem dicere Gorgiae uidetur, non in uerbis esse materiam sed in rebus. Iul. Vict., Rhet. 
El Arpinate, en definitiva, vinculaba a Sócrates con la tradición representada por los estoicos, atribuyéndole los mismos rasgos con los que caracterizaba a aquéllos 75 .

Pues bien, esta misma tesis es la que, en nuestra opinión, va a recoger Horacio en su Ars. Precisamente en esta epístola hace mención de la importancia de la res y de su influencia sobre la copia uerborum (AP 40-1) y más adelante ( $A P$ 311) repetirá la sentencia catoniana, formulándola con igual carácter lapidario: uerbaque prouisam rem non inuita sequentur.

Tal secuencia, por sí misma, no entraña especial sorpresa. Ahora bien, lo que sí nos ha llamado la atención es, en primer lugar, el hecho de que Horacio haya asociado tal formulación con la sapientia ${ }^{76} \mathrm{y}$, por lo tanto, con las tesis estoicas relativas a la prioridad de la sabiduría sobre el arte, esto es, de la res sobre el artificium, como señala Plinio el Viejo ${ }^{77}$. En segundo lugar, es singularmente significativo que Horacio haya adscrito tales planteamientos a Sócrates ${ }^{78}$. Esta interpretación horaciana de integrar la sentencia catoniana dentro de las tesis estoicas y adscribirle tal principio a Sócrates expresa, pues, el profundo grado de conocimiento que el Venusino poseía de los criterios retóricos de Cicerón. Esta circunstancia, a pesar de la importancia que tiene en la historia de los principios estéticos y a pesar del eco que ha merecido entre otros autores latinos, no ha sido debidamente comprendida por los comentaristas horacianos ${ }^{79}$. En efecto, en Propercio nos encontramos una reproducción fidedigna del planteamiento horaciano, al asociar sapien-

${ }^{75}$ Cicerón presentaba a Sócrates como un hombre amante de la sapientia y uirtus, pero despectivo hacia el delectare y mouere animos. Cf. A. Alberte, Cicerón ante la retórica, "Aspectos formales...".

${ }_{76}$ AP 309: Scribendi recte sapere est principium et fons.

7 Plin., Nat. XXIX 16: Non rem antiqui damnabant, sed artificium. S. Boscherini, Lingua e scienza greca nel De agricultura di Catone, Roma 1970, p. 21: «El mismo Plinio ha comprendido correctamente la posición de Catón"y.

${ }_{78}$ AP 310: Rem tibi Socraticae poterunt ostendere chartae.

79 En el comentario de Kiessling-Heinze al Ars poetica se señala que Horacio tendría delante los Memorabilia de Jenofonte. E. Norden en "Die Composition..." entiende tal referencia socrática como dirigida a la Academia antigua. Grant-Fiske en "Cicero's orator...", p. 22, atribuyen igualmente esta referencia a la Academia. R. K. Hack, o.c., p. 43, asocia este planteamiento horaciano al Cicerón dominado por la estética platónica, sin comprender la diferencia de Sócrates y Platón establecida por el Arpinate. H. Funke, o.c., pp. 155-6, remite esta opinión a Platón, al analizar el Ars poetica a la luz del Ión. A. Ortega, «El ingenio y la técnica al servicio de la poesía según la mente de Horacion, Helmantica 2, 1951, pp. 84-94, señala, al respecto (p. 90): «Creemos que Horacio piensa preferentemente en Platón, cuya lectura le era familiar, como insinúa en sat. II 3,11 . Sócrates, como es sabido, no escribió nada y sus discípulos recogieron las explicaciones del maestro". Esta circunstancia llama tanto más la atención cuanto que no se ha comprendido la tradición marcada 
tia y res, siguiendo la tradición estoica y catoniana, y al atribuirle tal doctrina a Sócrates ${ }^{80}$.

Así pues, dado que tradicionalmente se viene estudiando la figura de Sócrates y Platón como indisociables, no se ha reparado en reconocer el empeño del Arpinate por diferenciarlas. Tal identificación, por otra parte, ha motivado entre los filólogos clásicos profundas contradicciones a la hora de entender las distintas valoraciones del Arpinate sobre los criterios estéticos de ambos filósofos ${ }^{81}$.

Consiguientemente esta asunción de los criterios ciceronianos por parte de Horacio justifica el que aquél haya definido a Catón el Censor con los mismos atributos empleados anteriormente por el Arpinate. En efecto, así como Cicerón definia las orationes de Catón el Censor como horridulae, lo mismo va a hacer Horacio ${ }^{82}$. De él destacará la uirtus y los mores, como ya lo había hecho Cicerón ${ }^{83} \mathrm{y}$, al igual que el Arpinate, lo asociará a Ennio ${ }^{84} \mathrm{e}$, incluso, Horacio nos lo va a presentar en un ambiente socrático-estoico en el que el sermo socraticus está animado

por Lucilio, fuertemente influido por la corriente estoica, quien habla precisamente de los Socratici carti (ed. Marx, 709) y reflejada en Propercio, quien vincula los planteamientos estoicos a la filosofia socrática.

${ }_{80}$ Prop., II 34, 25-8: Lynceus ipse meus seros insanit amores!

Solum te nostros laetor adire deos.

Quid tua Socraticis tibi nunc sapientia libris proderit aut rerum dicere posse uias?

Evidentemente Propercio está asociando la sapientia a las rerum uias y, a la vez, atribuyéndole a Sócrates tal interpretación. Ahora bien, hay en este texto un término que corrobora tal dependencia ciceroniana, el término laetor. Recordemos que Cicerón contraponía laetor a gaudeo, considerando al primero como opuesto a la apatheia estoica mientras el segundo reflejaba una satisfacción intima que no confundia el control del espíritu. El hecho de que Propercio haya empleado en este texto dicha expresión como exaltación de la pasión frente a la apatheia está evidenciando una clara asunción del lenguaje filosófico utilizado por el Arpinate.

${ }^{81} \mathbf{M}$. Leeman en la "Discussión» a la ponencia de A. Michel, «La Théorie de la rhétorique chez Cicéron», Entretiens, XXVIII, Ginebra 1981, señala lo siguiente: «El autor (Cicerón) aparece como un platónico antiplatónico"s.

82 Or. 152: indicant orationes illae ipsae horridulae Catonis.

C. III 21, 9-12: Non ille, quemquam Socraticis madet sermonibus, te negleget horridus; narratur et Prisci Catonis saepe mero caluisse uirtus.

${ }^{83}$ Ep. I 19, 14: uirtutemne repraesentet moresque Catonis. cimur.

De rep. I 1: quo (Catone) omnes... quasi exemplari ad industriam uirtutemque du-

Cat. 69: Tantum remanet quod uirtute et recte factis consecutus sis.

84 AP 56-7: ... cum lingua Catonis et Enni sermonem patrium ditauerit.

Cat. 10: ... de quo praeclare familiaris noster Ennius... Las referencias a Ennio por parte de Catón el Censor son frecuentes en este tratado $(14 ; 16 ; 50 ; 73)$. 
por la moderada degustación del vino, como se puede observar también en el Cato maior ciceroniano ${ }^{85}$.

Por otra parte, en conexión con aquellos principios estoicos que definian al hombre ideal del estoicismo como uir sapiens, no es extraño que Cicerón utilizara aquel símil de que así como no es posible poner en manos de un perturbado un arma, así tampoco es lógico poner en manos de una persona carente de formación filosófica las armas de la retórica ${ }^{86}$. Pues bien, una imagen parecida nos la ofrece Horacio al final de su Ars sobre la figura del perturbado, evidenciándose con ello este grado de coincidencias: evidentemente el símil se basa en la asociación de naturaleza estoica, asumida por uno y otro, entre los conceptos de insanus o uesanus e insipiens.

Tal proximidad estética se reconoce nuevamente si hacemos referencia a los conceptos de uir y uirtus, asumidos por la tradición estoica. Cicerón no sólo había señalado la relación etimológica entre ambos términos sino que además calificaba positivamente toda actitud presidida por el valor etimológico de uir, al asociarlo a $u$ irtus $^{87}$. Así pues, frente al carácter muliebre del discurso Cicerón contraponía el valor de lo uirile condenando lo primero y elogiando lo segundo ${ }^{88}$. Horacio, de igual modo, hará mención a la relación etimológica de uir y uirtus ${ }^{89}$, elogiando toda manifestación que responda a dicha uirtus y condenando, consiguientemente, aquellas otras calificadas como muliebres.

${ }^{\text {zs }}$ Cicerón en Cat. 44-6 nos presenta la imagen de un Catón departiendo su velada en amena conversación con sus paisanos, al igual que Sócrates en el Simposio de Jenofonte, animado por el calor del vino. Horacio, del mismo modo (C. III 21, 9-12) nos ofrece ese mismo cuadro, recogiendo además la expresión acuñada por Cicerón del sermo Socraticus. Recordemos cómo entre los estoicos la degustación del vino era aceptada para la animación del sermo, mientras la embriaguez era rechazada (D. L., VII 118).

${ }^{86}$ De or. III 55: quarum uirtutum expertibus si dicendi copiam tradiderimus, non eos quidem oratores effecerimus, sed furentibus quaedam arma dederimus.

AP 472: certe furit, ac uelut ursus... indoctum doctumque fugat recitator acerbus; quem uero arripuit, tenet occiditque legendo.

G. C. Fiske, Lucilius and Horace. A Study in the Classical Theory of Inspiration, Madison 1920, p. 31: «Incluso el reflexivo Horacio que en las líneas finales del $A P$ ridiculiza la concepción del demens poeta, se somete frecuentemente a la fórmula convencional de la inspiración".

87 Tusc. II 43: appellata est enim ex uiro uirtus...

Ep. I 17, 41-2: ... aut uirtus nomen inane est, aut decus et pretium recte petit experiens uir.

${ }_{88}$ A. Alberte, Cicerón..., «Aspectos formales...». En este capítulo of recemos un repertorio amplio de ejemplos sobre tal particularidad.

${ }^{89}$ Cf. n. 87. 
Dentro de esta misma asunción de principios filosóficos se halla la valoración común sobre el uir bonus, valoración de ascendencia estoica. En efecto, una postura totalmente irreconciliable entre el estoicismo y los rétores, continuadores de las tesis de los sofistas, consistía en la distinta valoración sobre el ser y parecer honrado. Consiguientemente los estoicos mostrarán su total repudio hacia aquellos métodos retóricos tendentes a deformar la species recti. Un eco de tal sentimiento aparecía ya recogido por Lucilio ${ }^{90}$. Cicerón y Horacio se inscribían en esta misma línea del ser honrado frente al parecerlo de los rétores, aun cuando tal principio lo compatibilizaban con las demás funciones del orador, el delectare y el mouere animos ${ }^{91}$.

Desde esta misma posición común de exigir este tipo de sapientia sostenida por los estoicos vemos una idéntica actitud de rechazo de la filosofia epicúrea por insipiens. Recordemos, al efecto, cómo Cicerón en De finibus I, tras criticar a Epicuro por su falta de rigor en la fisica y por su ignorancia en la dialéctica, motiva el que aquél sea calificado de indoctus: (De fin. I 26) Addidisti ad extremum etiam indoctum fuisse. Esta misma crítica es la que ejerce Horacio en $C$. I 34, 1-3:

Parcus deorum cultor et infrequens insanientis dum sapientiae consultus erro

Horacio se está refiriendo, como señala su comentarista Porfirión, a la doctrina epicúrea, descalificándola de igual modo que Cicerón. Concretamente dice de ella que es insaniens, término éste sinónimo de stultus, insipiens, indoctus, como el mismo Horacio documenta y lo hemos comentado.

Por último, si Cicerón criticaba a los estoicos por limitarse a la res con total desafecto hacia los aspectos estéticos, de igual manera Hora-

${ }^{90}$ Luc. 1230-3 (ed. Marx): Vni se atque eidem studio omnes dedere et arti uerba dare ut caute possint, pugnare dolose blanditia certare, "bonum», simulare, "uirum» se insidias facere, ut si hostes sint omnibus omnes.

${ }^{9}$ De off. I 41: Totius autem iniustitiae nulla capitalior quam eorum qui tum maxime fallunt, id agunt ut uiri boni esse uideantur (cf. De off. I 65; II 43).

Ep. I 16, 52: Oderunt peccare boni uirtutis amore: tu nihil admittes in te formidine poenae... uir bonus, omne forum quem spectat et omne tribunal... labra mouet metuensque audiri "pulchra Lauerna, da mihi fallere, da iusto sanctoque uideri».

Sat. II 3, 40-1: ... Pudor, inquit, te malus angit insanos qui inter uereare insanus haberi. 
cio ejercerá la crítica contra aquellas formas desprovistas de atención literaria, utilizando el mismo lenguaje del Arpinate (AP 445-7 y Ep. I 18,5-8).

En definitiva, la asunción del concepto estoico de sapientia y consiguientemente de la exigencia del dominio de la res, la visión estoica de Sócrates, la relación etimológica entre uir y uirtus, la relación semántica entre insipiens e insanus, la necesidad de atender no sólo a la res sino también al ornatus es común a Cicerón y Horacio. Es difícil, por tanto, ignorar la ascendencia del Arpinate sobre Horacio en esta interpretación de la formación filosófica del orador y poeta.

\section{Atribución A LA FUNCIÓN DEL ORADOR Y POETA}

Desde esta concepción idealizada del orador y poeta Cicerón y Horacio llegan a convertirlos en figuras legendarias de la historia de la humanidad, al conferirles aquellos atributos observados en personajes mitológicos.

En efecto, Cicerón en su tratado retórico de juventud, De inuentione, señalaba la importancia del orador en la historia de la humanidad, al atribuirle la función de reconvertir al hombre de animal salvaje ajeno a toda obligación social en ciudadano civilizado. Esta misma atribución la vemos repetida en Horacio, pero lógicamente referida al poeta. Sin duda alguna, el De inuentione ciceroniano, trenzado sobre un amplio repertorio de textos retóricos, como su propio autor afirma ${ }^{92}$, estaría transmitiendo los tópicos habituales de esta tradición retórica y, por lo tanto, tal atribución horaciana bien podría situarse en el registro de los tópicos sin especial obligación con Cicerón ${ }^{93}$. Ahora bien, a juzgar por el número abundantísimo de citas de este tratado ciceroniano observadas en las obras retóricas posteriores ${ }^{94}$ así como por el escaso número

${ }_{92}$ De inu. II 2: Non unum aliquod proposuimus exemplum... sed, omnibus unum in locum coactis scriptoribus, quod quisque commodissime praecipere uidebatur, excerpsimus et uariis ingeniis excellentissima quaeque libauimus.

${ }_{93}$ Kiessling-Heinze, Sat. II 3, 98: "Se remontaba a la tradición epicúrea (Lucr., V 783...) llegando hasta Demócrito". Grant-Fiske, "Cicero's orator...", p. 65: "Éste es naturalmente un tópico retórico muy extendido». Fr. Wehrli, «Studien zu Cicero de oratoren, $M H$ 35, 1978, p. 76: el autor hace referencia a la larga tradición sobre la idea del progreso citando como textos señeros: Platón, Protagoras 318 ; Arquelao, Vorsokr. 60 A 4, 6; Lucrecio, V 925".

94 A. Alberte, "Implantación y evolución de la retórica latina», Estudios sobre drama y retórica en Grecia y Roma, León 1988, pp. 253-263. L. Calboli, C. Fortunatiani, Ars rhetorica, Bolonia 1979, pp. 5-6. 
de tratados retóricos escritos en latín en época clásica ${ }^{95}$, y en virtud de la ascendencia que un orador como Cicerón tenía sobre sus conciudadanos, no sería sorprendente que el tópico horaciano se inspirara en dicha obra. Por otra parte, si hacemos cotejo de ambos textos no podemos dejar de sentir la ascendencia ciceroniana sobre Horacio ${ }^{96}$ :

De diu. I 2: Nam fuit quoddam tempus cum in agris homines passim bestiarum more uagabantur et sibi ferino uictu propagabant. Nec ratione animi quidquam, sed pleraque uiribus corporis administrabant. Nondum diuinae religionis, humani officii... nemo nuptias uiderat legitimas... Quidam magnus et sapiens... dispersos in agris et tectis siluestribus abditos unum in locum congregauit...

$A P 391$ ss.: Siluestribus homines sacer interpretesque deorum caedibus et uictu foedo deterruit Orpheus...

... Fuit haec sapientia quondam publica priuata secernere, sacra profanis concubitu prohibere uago, dare iura maritis, oppida moliri, leges incidere ligno.

En ambos textos se descubre una misma estructura narrativa compuesta por dos partes. En la primera se describe una época prehistórica mostrándonos la vida salvaje de los hombres. En la segunda se narra la historia de la civilización, presentando como punto de arranque la aparición de la sapientia, y se nos muestran los grandes beneficios que tanto el orador como el poeta han deparado a la sociedad en virtud de la asunción de dicha sapientia. Incluso en el relato se encuentran testimonios suficientes para avalar tal dependencia. Vemos, en efecto, la utilización de expresiones comunes (siluestris, uictu), el paralelismo de imágenes comunes (in agris homines / siluestris homines; uictu ferino / uictu foedo; nuptias legitimas / concubitu prohibere uago).

No se puede ignorar, por otra parte, la ascendencia lucreciana sobre Horacio en la tradición de este tópico, como se revela a través de determinadas figuras y expresiones comunes ${ }^{97}$. Pero es, sobre todo, el hecho

95 Inst. III 1, 19: Romanorum primus, quantum ego quidem sciam, condidit aliqua in hanc materiam $M$. Cato, post Antonius inchoauit: nam hoc solum opus eius atque id ipsum imperfectum manet. Suet., Rhet. 25: Rhetorica quoque apud nos perinde atque grammatica sero recepta est.

* Esta misma tesis reaparecerá en otras obras del Arpinate: De or. I 33 ss.; Tusc. V 2, 5; Sest. 91. De todos modos el desarrollo expositivo de Horacio se basa claramente en el texto del tratado de inuentione.

${ }_{97}$ Tal influencia lucreciana se refleja más directamente en Sat. I 3, 109: quos Venerem incertam rapientes more ferarum uiribus editior...

En este texto nos encontramos determinadas expresiones, como more ferarum $o$ metonimias como Venus que habían sido empleadas por Lucrecio V 932 y 962. 
de haber convertido Cicerón al orador en encarnación de la eloquentia y sapientia lo que identifica de manera notoria a estos dos textos, desde el momento en que Horacio también convierte al poeta en integrador de belleza formal y sabiduría, frente a otras tesis, como la de los jurisconsultos, que negaban al orador tal capacidad, o la de los filósofos, que trasladaban tal facultad a su propio terreno ${ }^{98}$, o la del propio Aristóteles, quien consideraba al hombre animal político por naturaleza (Pol. I 1,2).

Así pues, aun cuando Horacio embellezca el texto de su Ars con la incorporación de personajes mitológicos (como ya había hecho en la Oda III 1), tanto la estructura narrativa como el empleo de expresiones comunes y, especialmente, la interpretación del poeta como uir sapiens et eloquens dejan entrever la influencia del De inuentione ciceroniano. En apoyo de este acercamiento de Horacio a tal interpretación ciceroniana conviene recordar que determinados antónimos presentes en el Ars (publica / priuata: sacra / profanis) aparecen profusamente empleados en la obra del Arpinate 99 .

\section{FUNCIÓN SOCIAL DEL ORADOR Y POETA}

De nuevo hallamos en Cicerón y Horacio este principio común de la utilidad social que el orador y poeta deben prestar a su patria ${ }^{100}$. Con-

${ }^{98}$ De or. 35: Tum Scaeuola, comiter ut solebat... Sed illa duo... uereor ut tibi possim concedere: unum, quod ab oratoribus ciuitates... constitutas et conseruatas esse dixisti. Tusc. V 5: Tu (sc. Philosophia) urbes peperisti, tu dissipatos homines in societatem uitae conuocasti... (cf. Tusc. I 62).

${ }_{99}$ Verr. IV 2 y 120 ; V 1. Har. resp. IX 14 y 56. Man. 53.

100 G. Williams, "Poetry in the moral climate of Augustan Rome», JRS 52, 1962, pp. 28-46: el autor señala cómo las Odas III 6 y 24 están motivadas por la voluntad de colaborar con la restauración moral. G. Remain, "Horace, Art poétique», $R P h$ 53, 1927, p. 244: «Los vv. 391-407 son un elogio de la poesía como madre de la civilización. Según Lejay es para disipar los prejuicios que podían tener contra ellos los romanos». H. L. Tracy, o.c., señala, refiriéndose a la Sat. I 10, 9-14, cómo Horacio ponía la poesía al servicio del pueblo. C. W. Macleod, "The Poetry of Ethics: Horace, Epistles I", JRS 69, 1979, p. 18: "Así pues, las epístolas de Horacio no eran una singularidad para la enseñanza filosófica sobre los hechos cotidianos". E. A. McDermot, "Greek and Roman elements in Horace's lyric programm», $A N R W$ II 31, 3, 1981, p. 1643: «Horacio y Virgilio estuvieron profundamente comprometidos con el papel de educadores de su pueblo, esto es, como uatesn. J. K. Newman, Augustus and the new poetry, Bruselas 1967: el autor en el cap. "The concept of Vates" (pp. 89-206) señala que la reintroducción por los poetas augústeos del arcaísmo uates respondia a la voluntad de adscribirle al poeta la función orientadora y educadora del oráculo. Frente a esta tesis se manifiesta L. P. Wilkinson, Gnomon 41, 1969, p. 157: «Demasiada importancia le ha sido dada al hecho de utilizar el término uates como poeta, lo que se convirtió en un clichén. 
cretamente el pasaje horaciano de la Ep. I 3,25 ss. es, en nuestra opinión, una glosa poética de aquel otro que Cicerón había escrito en $D e$ inu. I $1^{101}$. Colacionando ambos textos se puede reconocer, una vez más, el profundo grado de dependencia de Horacio con respecto al Arpinate:

De inu. I 1: Quare si quis, omissis rectissimis atque honestissimis studiis rationis et officii, consumit operam omnem in exercitatione dicendi is inutilis sibi, perniciosus patriae ciuis alitur. Qui uero ita sese armat eloquentia ut non oppugnare commoda patriae, sed pro his propugnare possit, is mihi uir et suis et publicis rationibus utilissimus atque amicissimus ciuis fore uidetur.

Ep. I 3,25: ... Quodsi...

frigida curarum fomenta relinquere posses, quo te caelestis sapientia duceret, ires.

Hoc opus, hoc studium parui nos properamus et ampli, si patriae uolumus, si nobis uiuere caris.

Horacio formula el tema a través de una argumentación semejante a la del Arpinate. En efecto, Horacio, en primer lugar, inicia el argumento con una oración condicional (quodsi), al igual que lo habia hecho Cicerón (siquis). En segundo lugar, establece como premisas las mismas que observamos en aquél: abandono de las frivolidades retoricistas y dedicación a la filosofia. En tercer lugar, presenta como conclusión tanto el beneficio propio como el social, al igual que aquél. Si bien el Arpinate llevado por la amplificatio desarrolla esta misma argumentación en forma positiva y negativa, esto es, presenta dos veces una misma argumentación, pero de manera diversa, Horacio, en cambio, formula una sola argumentación pero contaminando aquellas dos de Cicerón: presenta una argumentación formulada positivamente pero incluyendo elementos de la argumentación negativa del Arpinate.

Por otra parte, desde este planteamiento de servicio a la patria o utilidad social podemos recordar aquellas manifestaciones del Arpinate en las que aceptaba sumergirse en las tormentas políticas, esto es, en los peligros políticos, como también repetirá Horacio de manera muy semejante:

De rep. I 7: non dubitauerim me grauissimis... obuium ferre.

Ep. 1 1,16: nunc agilis fio et mersor ciuilibus undis ${ }^{102}$.

101 K. Gantar, "La prehistoire d'amicus sibi chez Horace», LEC 44, 1976, pp. 205-221. El autor ignora totalmente esta conexión señalada por nosotros remitiéndose al philautos aristotélico.

102 G. Lieberg, "Individualismo ed impegno politico nell'opera di Orazio", $P P$ 88, 1963, p. 353: «En la Oda a Lolio (IV 9) el homo beatus teme más al delito que 
Incluso en ambos autores observamos la comparación entre los servicios prestados a la patria por el militar y el intelectual, en este caso, el orador y el poeta. Así como Cicerón manifestaba de manera rotunda el superior beneficio del orador frente al militar, siguiendo la tradición estoica ${ }^{103}$, Horacio, al contrastar ambas figuras, desarrolla elogiosamente los grandes servicios prestados por el poeta a su patria con total ignorancia de las prestaciones del militar ${ }^{104}$. Este tema, que acabaría siendo un tópico en nuestra literatura, como podemos ver en el famoso capítulo del Quijote "Que trata del curioso discurso que hizo Don Quijote de las armas y de las letras", es un punto de coincidencia más entre ambos autores. Precisamente desde esta proyección social del hombre de letras es como mejor se comprende la admiración de Cicerón y Horacio hacia el pater Ennius, así como su común rechazo de los neotéricos ${ }^{105}$. Incluso la crítica que Horacio formula contra los admiradores de Calvo y Catulo se inspira, en nuestra opinión, en aquella misma que Cicerón había ejercido contra éstos:

Tusc. III 45: O poetam egregium (sc. Ennium)! quamquam ab istis cantoribus Euphorionis contemnitur.

Sat. I 10,18-9: ... neque simius iste nil praeter Caluom et doctus cantare Catullum.

a la muerte y no duda en morir por sus amigos queridos o por la patria: non ille pro caris amicis aut patria timidus perire). Evidentemente la sentencia horaciana ( $C$. III $2,13)$ dulce et decorum est pro patria mori, aun cuando se base en un texto de Tirteo, como señalan sus comentaristas, estaba reproduciendo aquellas mismas opiniones de carácter estoico que leemos en Cicerón: (De fin. II 76) Omnia pericula pro re publica, mori pro patria. Ibid. III 64: laudandus is sit, qui mortem oppetat pro re publica, quod deceat... De leg. II 5. Esta misma relación fue observada por H. Hommel, «Dulce et decorum", $R h M 111,1968$, pp. 219-52.

${ }_{103}$ De off. I 74: uere autem si uolumus iudicare multae res exstiterunt urbanae maiores clarioresque quam bellicae... (77) ut enim alios omittam, nobis rem publicam gubernantibus nonne togae arma cesserunt? Cf. De off. II 46; Brut. 255.

${ }_{104}$ Ep. II 1, 124...: Militiae quamquam piger et malus, utilis urbi, si das hoc, paruis quoque rebus magna iuuari: os tenerum pueri balbumque poeta figurat, torquet ab obscenis iam nunc sermonibus aurem, mox etiam pectus praeceptis format amicis...

${ }^{105}$ Cic., Or. 161. Att. VIII 5, 1. Hor. Ep. II 1, 50. AP 56. Cf. D. P. Shackleton Bailey, "Cicero and early latin poetry", ICS 8, 1983, pp. 239-49. E. A. McDermot, "Greek and Roman elements in Horace's Lyric Programm», ANRW II 31, 3, 1981, p. 1654: «El que Horacio no sintiera más que desprecio hacia el movimiento neotérico se basa en dos puntos: el silencio de Horacio hacia Catulo, primero, en sus Epodos y, luego, en sus Odas constituye un desdén. La única referencia a Catulo es un insulto... Este desprecio se extiende al seruum pecus o imitatores (Ep. I 19, 19)"). 
La palabra clave, reveladora de tal dependencia, es, pues, cantare. Evidentemente este reproche no podía dirigirse contra los principios formales, desde el momento en que Horacio había asumido las mismas tesis neotéricas sobre la elaboración de la obra literaria (Sat. I 4,9-10; I 9,23-4: $A P$ 290-4 y 388), sino contra aquella concepción de la producción literaria ajena al problema ético, tal como se evidencia en aquellos versos catulianos (XVI 5-6):

Nam castum esse decet pium poetam

ipsum, uersiculos nihil necesse est!

Desde el momento en que Horacio había considerado necesario formar al futuro poeta desde los principios del decus ( $A P$ 308), tales principios contemplaban no sólo el comportamiento del ciudadano sino también su propia expresión, como ya lo había desarrollado Cicerón en el De officiis, de clara ascendencia estoica:

(De off. I 98) sic hoc decorum quod lucet in uita mouet approbationem eorum quibuscumque uiuitur, ordine et constantia et moderatione dictorum omnium et factorum.

De ahí que Horacio, siguiendo tales pautas, llegue a decir frente a los imitadores catulianos:

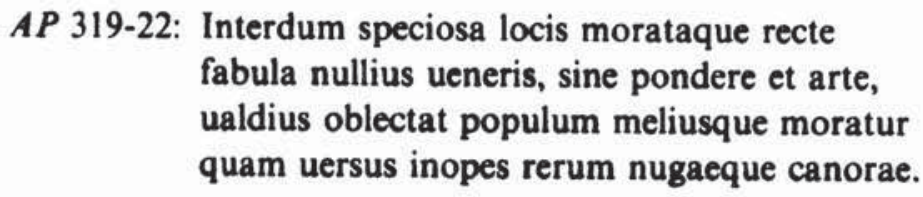

Evidentemente Horacio, como se puede ver en Ep. I 1,11 (quid uerum atque decens, curo et rogo et omnis in hoc sum) se sentía más identificado con estas exigencias éticas ampliamente desarrolladas en el tratado De officiis, presentes también en Paradoxa Stoicorum. Recordemos, al efecto, que el Arpinate en esta última obra, basada en tesis estoicas, muestra una vez más su rechazo hacia este tipo de poesía representada por Catulo, por considerarla ajena al problema ético: (26) poetam non audio in nugis. El rechazo de Horacio hacia los catulianos estaba, pues, más vinculado con estos principios éticos de gran ascendencia estoica, coherentes, por otra parte, con la reconstrucción moral impulsada por Augusto ${ }^{106}$, que con aspectos literarios, como se señala en el comenta-

106 G. Williams, The Nature of Roman Poetry Londres 1970, p. 14: «Horacio, más que ningún otro poeta augústeo, expresó la idea de que la poesía tiene una función social y tuvo la oportunidad de demostrarlo mejor que ningún otro». 
rio de Heinze a las Sátiras (o.c., p. 163). En este sentido se comprende su distanciamiento no sólo de los catulianos sino también de los bucólicos, así como su aproximación a la lírica griega más antigua, como nos hace ver J. H. Waszink ${ }^{107}$. No es extraño, por lo tanto, que en la misma Epistola a Augusto hable de la moralización emprendida por aquél (Ep. II 1,2-3) y de la función educadora del poeta (v. 126 ss.). Esta misma función educadora es también la que se puede reconocer en la obra ciceroniana $O r$. 144, al pretender hacer mejores a sus conciudadanos, siguiendo en esto aquella tradición socrático-platónica. En virtud de tal interpretación vemos cómo Horacio, al igual que Cicerón, asume la identificación del filósofo con el médico ( $E p$. I 2), procurando que el poeta se identifique con tal misión filosófica o moralizadora y cómo, de igual modo, basa la uirtus no en principios de sangre sino en principios morales ${ }^{108}$.

En definitiva, no sólo hay una postura coincidente entre ambos autores en el reconocimiento de la misión social que debe incumbirle al escritor, sino que además se puede observar la readaptación poética hecha por Horacio sobre estas mismas tesis defendidas por el Arpinate.

\section{CONCEPCIÓN DE LA POESIA}

Si los criterios sobre el ideal del orador y poeta son concurrentes en uno y otro autor, las opiniones sobre la materia y el arte revelan el mismo grado de afinidad.

Cicerón en el Orator marcaba claramente la diferencia entre la auténtica poesía, esto es, la poesía inspirada y sublime, y aquella otra

107 J. H. Waszink, "Der dichterische Ausdruck in den Oden des Horaz", Wege der Forschung, IC, 1972, pp. 288-9: «Lo primero que conviene señalar es el hecho de que Horacio ha aspirado a distanciarse de la lírica subjetiva de los neoteroi e igualmente de la poesía elegíaca y bucólica de su tiempo... buscando al propio tiempo en la lírica griega más arcaica los modelos poéticos, especialmente en Alceo, cuya poesía ha sido caracterizada como la más impersonal o suprapersonal de todas".

108 Sat. I 41, 120-1: ... sic me / formabat puerum dictis.

B. Stenuit, "Les parents d'Horace», LEC 45, 1977, pp. 125-44. Cic., De rep. II 24: nostri illi etiam tum agrestis uiderunt uirtutem et sapientiam regalem, non progeniem quaeri oportere. H. Roloff, «Maiores bei Cicero", Wege der Forschung, XXXIV, 1983, pp. 274-322. El autor destaca cómo Cicerón al oponer los conceptos homo nouus / homo nobilis apelaba al concepto de uirtus para delimitar más claramente su aportación social. Así dice de él (p. 279): "Por medio de la afirmación de la propia uirtus Cicerón se equiparará a los nobiles" y señala también cómo, según aquél, sólo los omnes boni son los verdaderos padres de la patria, sintiéndose él mismo un miembro más de tal sociedad. 
simplemente versificada, llegando a considerar más poética la prosa de Platón y Demócrito que la de los comediógrafos.

La opinión de Horacio en este punto es totalmente coincidente con la del Arpinate, circunstancia ésta que no tiene nada de extraño porque en esta misma línea de exigencia se hallaba no sólo la opinión de Quintiliano, profundo admirador de Cicerón, sino también la del autor del tratado De sublime ${ }^{109}$. Ahora bien, lo que sí llama poderosamente la atención es el hecho de que la opinión de Horacio esté desarrollada sobre las pautas ciceronianas. En efecto, Horacio formula poéticamente lo que el Arpinate había expresado en prosa, como se puede comprobar contrastando ambos textos:

Or. 67: Itaque uideo uisum esse nonnullis, Platonis et Democriti locutionem, etsi absit a uersu, tamen quod incitatius feratur et clarissimis uerborum luminibus utatur, potius poema putandum quam comicorum poetarum; apud quos, nisi quod uersiculi sunt, nihil est aliud cotidiani dissimile sermonis.

Sat. I 4,45-8: Idcirco quidam comoedia necne poema esset quaesiuere, quod acer spiritus ac uis nec uerbis nec rebus inest, nisi quod pede certo differt sermoni, sermo merus.

Aquí se puede observar, en primer lugar, la misma secuencia argumentativa:

1. Horacio recoge, al igual que Cicerón, la opinión tradicional, si bien el Arpinate la expresa a través de la fórmula nonnullis uisum esse, mientras Horacio lo hace mediante el quidam quaesiuere.

2. Horacio establece este status quaestionis definitiuus sobre los términos poema y comoedia, como también lo había hecho el Arpinate, fijando, de igual modo, el criterio diferenciador no sobre la metrificación sino sobre la elevación del pensamiento y la belleza de la forma.

3. Horacio concluye el silogismo señalando que la comoedia se distingue del sermo sólo por el verso, conclusión a la que había llegado Cicerón.

En segundo lugar, es imperioso destacar cómo la parte más importante de esta argumentación, la conclusión, es en el caso de Horacio una evidente poetización de aquella que había formulado el Arpinate ${ }^{110}$.

${ }^{109}$ Precisamente este tratado hará abstracción de las fronteras entre prosa y poesía, analizando la obra por su fuerza e inspiración. W. Kroll, $M$. Tulli Ciceronis Orator, Münster 1913, p. 70: "Cicerón reproducirá aquí los puntos de vista de Teofrasto". Kiessling-Heinze, Sat. I 4, 43: "Al incitatius ferri de Cicerón se corresponde en Horacio el acer spiritus et uism.

110 Horacio está demostrando, a través de esta argumentación, no sólo su dominio de este recurso dialéctico, ampliamente atendido por Cicerón en el De inuentione, sino también de los status quaestionis, igualmente detallados en dicho tratado. Preci- 
Recordemos, por otra parte, que así como Cicerón marcaba una clara diferencia entre sermo y oratio "II, caracterizando a la oratio por el ornatus y atribuyéndole el calificativo de diuina, Horacio también distinguirá la poesía inspirada y divina de aquel sermo humilde y vulgar ${ }^{112}$. $\mathrm{Y}$ así como Cicerón reservaba para el orador o uir eloquens la oratio, de igual modo Horacio señalará que el poeta auténtico se distingue por el poema y no por el sermo ${ }^{113}$. Consiguientemente es un error adscribirle a las Sátiras horacianas el nombre de sermones como nombre propio, puesto que el término sermo había sido claramente definido por aquél como uso común de la lengua latina frente al uso poético resuelto onomasiológicamente con el término de poema: evidentemente el Venusino adscribía tanto las Sátiras como las Epístolas a la categoría del sermo ${ }^{114}$.

samente en esta misma sátira (v. 63 ss.) nos presenta el desarrollo de una quaestio qualificatiua, esto es, una quaestio basada en el carácter justo o no del asunto.

III Cicerón, al oponer los términos sermo y oratio, está reservando las funciones literarias a la oratio, mientras el sermo queda limitado a funciones propiamente comunicativas. Precisamente desde el punto de vista formal Cicerón exigirá el ornatus para que se cumpla la función estética requerida por la oratio. Cf. Or. 64; 113-4.

112 Precisamente Grant-Fiske en "Cicero's orator...", señalan el carácter divino reconocido por Horacio a la poesía elevada, vinculando tal opinión con la emitida por Cicerón en Tusc. V 5. R. Kilpatrick, "Horace on his critics: epist. 1, 19», Phoenix 29, 1975, p. 325: «La verdadera poesía nada tiene que ver con un Cratino, poeta beodo, y mucho menos con los aspectos negativos imitados por el seruom pecus'. En efecto, Horacio considera la poesía lírica tan sublime como la poesía de la tragedia o epopeya ( $C$. I 1,36 ; III 25, 17; IV 2,23 , etc.). De ahí que en la última Oda del 1. III, que constituye el epílogo de su actividad como poeta lírico, tal como él mismo lo presentaba, invoque el patrocinio de Melpómene, musa de la tragedia. De este modo, el propio poeta estaba equiparando el valor literario de su producción lírica con el de la tragedia, como ha reconocido también M. Lejay en el prólogo (p. XXI) de la ed. de Horacio (Classiques Hachette). Frente a tal opinión el propio Venusino nos dirá de sus Sátiras y Epístolas que su nivel era tan humilde como el de la comedia, calificándolas a todas ellas con el término de sermo (Ep. II 1, 165 y 250-1; Ars 229). A este respecto señala P. Grimal («Horace, De l'Art de vivre», BAGB, 1964, p. 438): «En relación con la poesía él ha establecido la comparación entre las Sátiras y la obra de los comediógrafos griegos señalando precisamente que si se quita el ritmo ya no hay verdadera poesía (Sat. I 4, 2 y 46-7, 52-62)». A. La Penna, Orazio, Satire e Epistole, Florencia 1957, p. XX: «La Sátira quiere adecuarse a la inmediatez de la lengua viva; a tal efecto, tiende a la utilización generosa de voces tomadas del sermo cotidianus». Tal opinión será repetida por B. Stenuit, "Les parents d'Horace», o.c., p. 134: «la lengua familiar es una característica de la Sátira». Cf. G. Bonfante, EMERITA 4, 1936, pp. 86-119 y 209-247, y 4, 1937, pp. 17-88.

${ }^{113}$ Ep. II 2, 58-60: denique non omnes eadem mirantur amantque:

carmine tu gaudes, hic delectatur iambis, ille Bioneis sermonibus et sale nigro.

En este resumen de su actividad literaria Horacio está jerárquicamente marcando la importancia de la misma.

114 Evidentemente, como se lee en Schanz-Hosius (Geschichte der Römischen Literatur, II, p. 125) el término sermo es usado por Horacio para referirse bien a las Sá- 
Así pues, la reproducción poética por parte del Venusino de esta quaestio establecida por Cicerón en torno a la definición de comoedia y poema es tanto más significativa de tal vinculación a las tesis ciceronianas cuanto que la tradición escolar venía planteando la discusión sobre poema en un plano totalmente distinto, el de su delimitación semántica frente al término poesis, como nos documenta Diógenes Laercio y se puede comprobar en Lucilio, Varrón o Filodemo ${ }^{115}$.

En conclusión, la concepción horaciana sobre la poesía estaba aherrojada en las mismas categorias estéticas observadas en Cicerón, llegando, incluso, a utilizar las mismas formulaciones que aquél.

\section{EL PRINCIPIO DEL DECVS}

Una vez comprobada la unanimidad de ambos autores sobre el producto artístico, pasemos revista al grado de coincidencias en torno a los aspectos constitutivos de la obra de arte y, por tanto, a los fundamentos del arte literario.

El principio del decus constituía para Horacio, al igual que para $\mathrm{Ci}$ cerón, el criterio básico de toda actividad literaria: (De or. I 132) caput esse artis decere. En efecto, el Arpinate en Or. 123 vincula el ideal oratorio al dominio de tal principio: Is erit eloquens qui ad id quodcumque decebit poterit accommodare orationem. Horacio, al igual que Cicerón, le prestará atención singular a este principio en el Ars Poetica ${ }^{116}$ y, así

tiras, bien a las Epístolas, bien a ambas a la vez. No creemos, por lo tanto, como señala Porfirión en su comentario (Sat. I 1 ad initium), que haya que atribuirle a Horacio el título de sermones con el que han sido transmitidos los dos libros de Sátiras. Quintiliano no nos hace suponer tal circunstancia al referirse a Horacio como autor de Sátiras (Inst. X 1, 94-6), género típicamente romano, según aquél. Circunstancia paralela es la que ocurre con el término de Odas transmitido por la tradición y usado también por Porfirión en su comentario, frente a lyrica o carmina usados por Horacio.

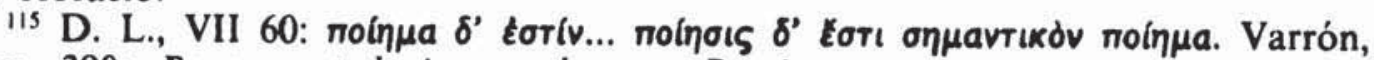
Men. 390: Poema est lexis eurythmos... Poesis est perpetuum argumentum ex rhythmis... Poetice est ars earum rerum.

Luc. 339 (ed. Marx): ... primum hoc, quod dicimus esse poema, pars est parua poema. illa poesis opus totum (tota[que] Ilias una est, una ut ЭÉoıs annales Enni) atque opus unum est, maius multo est quam quod dixi poema.

P. Boyancé, "Ả propos de l'art poétique d’Horace», $R P h$ 62, 1936, pp. 20-22. A. L. Ford, A Study of early Greek Terms for Poetry: "Aoide», "Epos" and "Poiesis", U.M.F., Yale University, 1981. Cf. "Poiesis and the art of Poetry», pp. 311-321. Es evidente, al trasluz de este estudio, que los conceptos sobre poesis y prema utilizados por los romanos están vinculados al período helenístico.

${ }^{116}$ De or. II 85: temptabo quid deceat...

AP 306-8: ... docebo quid deceat, quid non. 
como el Arpinate orientaba la función del decus dentro del terreno literario a la adecuación entre asunto y expresión o entre personaje y lenguaje, del mismo modo Horacio exigirá esta misma adecuación ${ }^{117}$. Dicho principio estético estaba vinculado, según el Arpinate, a la sapientia o prudentia ${ }^{118}$ y consiguientemente nunca podría ser atendido por un tratado retórico: (De or. III 132) decere, quod tamen unum id esse quod tradi arte non possit. Por lo tanto Cicerón en este caso concreto estaba siguiendo aquellas corrientes filosóficas interesadas por armonizar el hecho con su propia circunstancia. Según tales premisas la vida humana debería estar regulada por determinadas pautas naturales mostradas a través de la ratio y, paralelamente, toda actividad literaria debería estar formalizada según este mismo principio ${ }^{119}$.

Horacio asume estas mismas tesis ampliamente desarrolladas por el estoicismo, como se documenta en el De officiiis ${ }^{120}$, llegando, incluso, a utilizar la formulación ciceroniana sobre la conveniencia de acomodar la conducta humana a las pautas naturales ${ }^{121}$. En consecuencia señalará, al igual que Cicerón, que es el uir sapiens el que mejor capacitado está para atender a tal principio del $\operatorname{decus}^{122} \mathrm{y}$, al igual que aquél, ex-

117 De or. III 210 : ... nunc quid aptum sit, hoc est, quid maxime deceat in oratione uideamus. Or. 74: decere quasi aptum consentaneumque tempori et personae. De or. III 53: Qui idem ita moderantur ut rerum, ut personarum dignitates ferunt.

${ }_{118}$ De or. III 210: Scire quid quandoque prudentiae est. Or. 123: Haec sapientia maxime adhibenda eloquenti est ut temporum personarumque moderator. De off. I 14: nec uero illa parua naturae est rationisque in factis dictisque qui sit modus.

${ }_{119}$ Or. 71-2: semperque in omni parte orationis ut uitae quid deceat est considerandum; quod et in re, de qua agitur, positum est et in personis, et eorum qui dicunt et eorum qui audiunt. Itaque hunc locum longe et late patentem philosophi solent in officiis tractare. Cf. De fin. III 61, 73; IV 14. Tusc. V. 82. De off. III 13.

${ }^{120}$ O. A. W. Dilke, "The interpretation of Horace's Epistles», $A N R W$ II 31, 3, 1981 , pp. 1837-57. Este autor señala cómo los términos decet, decens, decenter utilizados por Horacio están basados en el estoicismo paneciano, del que, precisamente, Cicerón es una de sus mejores fuentes. A. Fontán, "Cicerón y Horacio...», o.c., p. 212: «El principio del decus es también ciceroniano y horaciano. Cicerón además del decus crea el neologismo decens").

121 De fin. III 61: opportunitatis esse beate uiuere, quod est conuenienter naturae uiuere. Esta expresión conuenienter naturae uiuere aparece pródigamente repetida en la obra del Arpinate como fórmula filosófica (De fin. III 73; IV 14. Tusc. V 82. De off. III 13). Dicha fórmula, como señala W. Dilke, o.c., p. 1848, es la versión griega

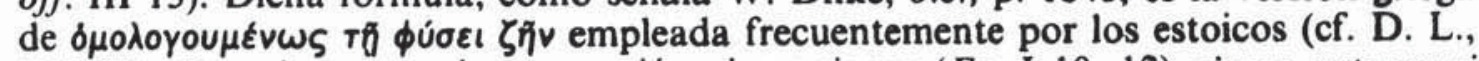
VII 87). Horacio recogerá esta versión ciceroniana: (Ep. I 10,12) uiuere naturae si conuenienter oportet.

${ }_{122}$ Ep. II 1, 66-8: Si quaedam nimis antique, si pleraque dure dicere credit eos, ignaue multa fatetur, et sapit et mecum facit et loue iudicat aequo.

AP 309: Scribendi recte sapere est principium et fons. 
tenderá tal principio literario a la adecuación entre asunto y lengua, esto es, entre res y uerba, y entre lengua y personaje ${ }^{123}$.

Por otra parte, el principio del decus encontrará en el modus una de sus más sólidas concreciones, como vemos en ambos autores. Recordemos, al efecto, cómo Cicerón subsumía el principio del modus dentro de esta categoria superior que era el decus (De off. I 114: modus... est optimus decus ipsum tenere nec progredi longius) y cómo lo vinculaba también a la natura y ratio (De off. I 14: nec uero illa parua uis naturae est rationique... in factis dictisque qui sit modus). Horacio presentará igualmente el modus bajo la óptica del decus, fijando también como criterios de aquél la natura (Sat. I 2,111-3) y la ratio (Sat. II 3,265-71).

Así pues, según ambos escritores toda expresión literaria deberá estar situada dentro de los propios límites impuestos por esta exigencia del modus, esto es, deberá evitar tanto el exceso como el defecto ${ }^{124}$. Consiguientemente expresiones como suus cuique modus (De off. I 14) o est modus in rebus (Sat. I 1,106) están reflejando tal principio del decus.

Es evidente, pues, que si tal principio había sido asumido por determinadas corrientes filosóficas, como fundamento estético de sus planteamientos literarios $-\mathbf{R}$. H. Hack lo vincula a las ideas platónicas ${ }^{125}$ - no es menos cierto que la formulación de tal principio, observada en uno y otro autor, nos hace pensar en la ascendencia de Cicerón sobre Horacio en este punto concreto.

\section{UnidAD y ARMonia DE LA ObRa DE ARTE}

Así como el principio del decus tenía sus raices últimas en las ideas platónicas, de igual modo el concepto sobre la unidad y armonía de la obra literaria se remontaba a dichas ideas, como manifiesta el propio Cicerón.

Consiguientemente si Cicerón asumía con relación al concepto de la obra de arte aquellos principios platónicos relativos a la unidad y armonía, es lógico que, al igual que había visto en los diálogos platóni-

${ }^{123}$ C. I 6, 9: Conamur, tenues grandia...

Sat. II 4, 9: Vtpote res tenues, tenui sermone peractas.

AP 229: migret in obscuras humili sermone tabernas.

124 De off. I 141: modus... est optimus decus ipsum tenere... nec progredi longius.

Sat. I 1, 106-7: Est modus in rebus, sunt certi denique fines quos ultra citraque nequit consistere.

125 R. K. Hack, o.c., p. 92: «El énfasis puesto sobre el decus se debe a la exigencia de una ley superior: las ideas platónicas". Concretamente en el Fedro 270 a se señala que sin conocimiento no se puede of recer lo conveniente. 
cos, acudiera al símil del cuerpo como ilustración de tal idea ${ }^{126}$. No es extraño, en tal sentido, que Horacio, defensor también de la unidad y armonía de la obra de arte, acudiera también a dicho símil ${ }^{127}$.

En esta misma línea de coincidencias estéticas conviene igualmente tener presente el hecho de que Horacio haya utilizado las referencias a la escultura y pintura como claves informativas de tales principios literarios. Cicerón se había referido reiteradamente a la escultura y pintura para ilustrarnos sobre la oratoria romana, «siguiendo un lugar común de la retórica antigua»" ${ }^{128}$. Por lo tanto el hecho de que ambos autores hayan acudido a tal lenguaje para documentarnos sobre el carácter artístico de la obra literaria no tiene por qué sorprendernos. Pero, por otra parte, no sería aventurado sugerir que la formulación comparativa empleada por Horacio (AP 361: ut pictura poesis) viene a ser un calco condensado de aquellas otras formulaciones ciceronianas: ut pictor ille, ut pictores, etc. ${ }^{129}$ Horacio en este caso como en otros ya observados muestra su capacidad para la condensación de las mismas ideas expresadas por el Arpinate.

Más aún, si Horacio con relación a estos principios estéticos está incurso en una tradición de la que es solidario el Arpinate, en el empleo de determinados recursos expresivos su dependencia ciceroniana nos parece defendible. Recordemos, en este sentido, cómo el propio Cicerón había señalado las dificultades lingüísticas para atender a las demandas léxicas en el terreno filosófico y cómo uno de sus mayores empeños consistía en equipar al latín de un lenguaje filosófico y técnico capaz de satisfacer tales exigencias culturales. En este sentido no es extraño que los escritores posteriores lo tuvieran en cuenta desde este punto de vista lexicológico ${ }^{130} \mathrm{y}$, evidentemente, Horacio no fue una excepción. En efecto, con relación a la unidad de la obra el Arpinate toma como criterio las ideas platónicas. A tal objeto traduce $1 \delta \varepsilon a$, refiriéndose a la idea platónica - punto de referencia obligada para la realización de cualquier actividad artística-, a través de términos tales como forma y spe-

126 Gorg. 506 d. Fedro 264 b-e. De off. I 98: Vt enim pulchritudo corporis apta compositione membrorum mouet oculos et delectat hoc ipso quod inter se omnes partes cum quodam lepore consentiunt.

${ }_{127}$ P. Boyancé, "Ả propos de l'Art poétique...», p. 25: «Sobre conceptos generales no podemos olvidar su vinculación platónica en lo referente a la unidad de la obran.

128 G. A. Kennedy, "Theophrastus and stilistic Distinctions", HSPh 62, 1957, p. 99: «La comparación de artistas y oradores se convierte en lugar común de la retórica antigua».

${ }_{129}$ De or. II 73; III 195. Brut. 70; 228; 257. Or. 65; 74. Antecedentes de este símil se pueden encontrar en Gorg. 503 e.

130 A. Alberte, "Consideraciones sobre la trascendencia lexicológica de Cicerón", Durius 4, 1974, pp. 209-20. 
cies: (Or. 10) has rerum formas appellat lokas ille non intellegendi solum sed etiam dicendi grauissimus auctor et magister Plato. Dicha idea platónica, sólo alcanzable a través de la mente, se caracteriza, según Cicerón, por ser simplex et una (Ac. I 35 y 40). Pues bien, en el Ars Poetica Horacio hará referencia a la forma una: (AP 8-9)... ut nec pes nec caput uni / reddatur formae.

Horacio está, pues, reproduciendo el lenguaje ciceroniano para referirse a las ideas platónicas así como también a la caracterización de tales ideas: (AP 23) Denique sit quod uis, simplex dumtaxat et unum. No creemos, por tanto, que tal concepto horaciano haya que adscribirlo directamente a las teorías aristotélicas, como señala P. Grimal ( La Théorie des genres littéraires dans l'Art Poétique d'Horace», en Los géneros literarios. Actes del VII Simposi d'Estudis Clàssics, Barcelona 1985, pp. 7-19).

En segundo lugar, con relación a la armonía de la obra los términos temperare y moderare son usados por Horacio con el mismo valor que les había conferido el Arpinate. Concretamente en los textos filosóficos del Arpinate vemos cómo estos términos son empleados con el valor específico de "ordenamiento según armonía cósmica» y con esta especialización semántica tales términos son aplicados no sólo al control del alma sino también al gobierno del estado o a la producción literaria ${ }^{131}$. Tales conceptos estaban vinculados, en definitiva, a los criterios de la ratio y consilium. Así pues, el uir sapiens, según estos criterios filosóficos de clara ascendencia estoica, deberá saber gobernar su espíritu no dejándose llevar por las pasiones, como pudiera ser la alegría desafora$\mathrm{da}^{132}$. Y si a Júpiter, como personificación de la ratio universal, le compete por su sapientia gobernar el cosmos, esto es, ejercer la función del temperare o moderare, del mismo modo el princeps ciceroniano estaba representado por el orator perfectus ${ }^{133}$. En coherencia con tales plantea-

131 Tim. 42: in qua (temperatione) omnem animum uinuersae naturae temperans permiscebit. Tusc. I 2: rem... publicam nostri maiores certe melioribus temperauerunt et institutis et legibus. Ac. II 3: in eodem tanta prudentia fuit in constituendis temperandisque ciuitatibus. De off. I 3: Hoc quoque colendum est aequabile et temperatum orationis genus.

132 Tim. 42. De leg. II 22: "Loedis publicis... popularem laetitiam in cantu et fidibus et tibiis moderanto".

133 De nat. deor. III 87: quod (sc. Iuppiter) nos iustos, temperatos, sapientes efficiat. De rep. VI 26: qui tam regit et moderatur et mouet id corpus... quam hunc mundum ille princeps deus. De rep. I 34: perfecti oratoris moderatione et sapientia non solum ipsius dignitatem, sed et priuatorum plurimorum et uniuersae rei publicae salutem maxime contineri. De or. III 63: procul abest tamten ab eo uiro quem quaerimus, et quem auctorem publici consilii et regendae ciuitatis ducem et sententiae et eloquentiae principem in senatu, in populo, in causis publicis esse uolumus. 
mientos toda actividad literaria deberia estar regulada, según Cicerón, por el mismo principio de la moderación.

Pues bien, en Horacio vemos no sólo la plena asunción de tales ideas recogidas por el Arpinate en sus tratados filosóficos sino también la aplicación del mismo lenguaje. Concretamente Horacio utilizará los términos temperare y moderare con los mismos valores observados en la obra del Arpinate, esto es, como manifestaciones o realizaciones del consilium o ratio ${ }^{134}$. Consiguientemente tanto al referirse al gobierno del alma como al de la ciudad utilizará las mismas expresiones que Cicerón, si bien, en este último caso, el princeps temporal ya no estará encarnado en la figura del orator sino en la de Augusto ${ }^{135}$. De igual modo, al referirse al control de la actividad literaria, utilizará el mismo lenguaje del Arpinate ${ }^{136}$.

Más aún, si con relación al gobierno del alma Cicerón consideraba la laetitia pasión del alma frente al gaudium, del mismo modo vemos cómo en Horacio el término laetitia es asumido con este mismo valor negativo, debiendo la moderatio o temperantia del uir sapiens corregir tal desequilibrio ${ }^{137}$.

\footnotetext{
${ }^{134}$ Ep. II 2, 59-60: ... qui non moderabitur irae,

Sat. II 3, 265-7: ... o ere, quae res

nec modum habet neque consilium, ratione modoque tractari non uolt...
}

Evidentemente este texto, como se señala en el comentario de Heinze, está basado en Terencio, Eun. 57-8. Ahora bien, conviene tener presente, por otra parte, que el Arpinate habia citado precisamente los vv. 59-63 en Tusc. IV 76.

135 Júpiter personalizará, de igual modo, la razón universal y será moderator o temperator del universo:

C. I 12, 10-13: Quid prius dicam solitis parentis

laudibus, qui res hominum ac deorum

qui mare ac terras uariisque mundum comparat horis?

De igual modo habrá un princeps que gobernará a imagen de Júpiter: C. I 12, 52-3: ... Tu secundo / Caesare regnes.

D. Pietrusiński, "L'Apotheosis d'Octavien Auguste par la parallèle avec Juppiter dans la poésie d'Horace», Eos 68, 1980, p. 113: "Cicerón se sirve de moderatio y temperatio para referirse a esta armonia». E. Fränkel, Horace, Oxford 1957, p. 344, n. 2. El autor, para justificar el significado que Horacio le presta a estos términos remite a citas ciceronianas, como De off. III 119 y Ti. 22. J. C. Davies, "The originality of Cicero's philosophical Works", Latomus 30, 1971, p. 111. El autor señala la trascendencia que la teoría de Cicerón habria de tener en la política de Augusto e indica (p. 113) el eco que las exigencias de la moderación y equilibrio mostradas en los tratados ciceronianos De legibus y De republica alcanzaron en las Odas de Horacio.

${ }_{136}$ Ep. I 19, 28-9: temperat Archilochi Musam pede mascula Sappho, temperat Alcaeus, sed rebus et ordine dispar.

137 Tusc. IV 66: Atque ut conficere decet, timere non decet, sic gaudere deceat, laetari non decet. Tusc. V 69: quo... gaudio adfici necesse est sapientis animum. 
En definitiva, Horacio no sólo se incardina en estos mismos principios estéticos de Cicerón sino que, además, utiliza el lenguaje que aquél había fijado técnicamente.

\section{Prodesse et DELECTARE}

Otro de los principios estéticos profundamente arraigados en la obra de Cicerón y Horacio es el que hace referencia al prodesse et delectare, cuya ascendencia platónica es igualmente reconocida por el Arpinate.

Así pues, aun cuando se suele considerar el prodesse et delectare horaciano como un furtum de la obra de Neoptólemo de Parion ${ }^{138}$, no podemos ignorar que Horacio vinculaba tal principio a la utilitas y delectatio $^{139}$. Consiguientemente no podemos dejar de señalar la gran atención que Cicerón le había prestado a estos dos principios no sólo como crítico de arte sino también como filósofo. En efecto, en su tratado De natura deorum II 22 Cicerón explicaba la configuración del cosmos desde estos dos principios ${ }^{140} \mathrm{y}$, en coherencia con tales planteamientos, interpretaba de la misma manera la obra literaria, como se puede ver en el De oratore ${ }^{141}$. Aunque estos dos principios fueran asumidos por los tratados retóricos y poéticos posteriores como un tópico literario, no es menos cierto que Cicerón los contemplaba desde una óptica diferente a la de determinadas corrientes literarias. Así, en efecto, nos dice de Torcuato, representante del epicureísmo, que éste le negaba a la poesía

\section{II 3, 1-4: Aequam memento rebus in arduis seruare mentem, non secus in bonis ab insolenti temperatam laetitia...}

Esta misma moderación contra la alegría desaforada es la que Catón el Censor va a exigir en el discurso en favor de los Rodios, siguiendo, por tanto, las tesis estoicas sobre el control de los sentimientos.

${ }^{138} \mathrm{H}$. J. Mette, "Neoptolemos von Parion», o.c., señala cómo la expresión rép-

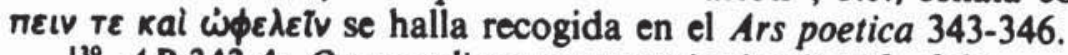

139 AP 343-4: Omne tulit punctum qui miscuit utile dulci lectorem delectando, pariterque monendo.

140 Talis igitur mens mundi... in his maxime est aucupata, primum ut mundus quam aptissimus sit ad permanendum, deinde ut nulla re egeat maxime autem ut in eo eximia pulchritudo sit atque omnis ornatus.

141 De or. III 178: Sed ut in plerisque rebus incredibiliter hoc natura est ipsa fabricata, sic in oratione, ut ea quae maximam utilitatem in se continerent, plurimum eadem haberent uel dignitatis uel saepe etiam uenustatis... Haec tantam habet uim, paulum ut inmutata cohaerere non possint, tantam pulchritudinem ut nulla species ne cogitari quidem possit ornatior. 
toda utilidad ${ }^{142}$, mientras en el polo opuesto nos presenta a aquellos otros filósofos ajenos al deleite literario ${ }^{143}$.

Cicerón, al participar en esta polémica, señala cómo determinados textos filosóficos escritos con belleza agradan, aun cuando sus opiniones difieran de las del lector ${ }^{144}$, mientras, por el contrario, son repudiados aquellos otros que no atienden a tal circunstancia, como era el caso del propio Epicuro ${ }^{145}$. Consiguientemente el Arpinate sentenciará sobre tal extremo: (Tusc. II 7) lectionem sine ulla delectatione neglego ${ }^{146}$.

Evidentemente el maridaje entre utilitas y delectatio, sostenido por el Arpinate, contaba con una larga tradición ${ }^{147}$, y aquél no dejará de atribuirle tal principio estético a Platón. Concretamente el símil de la nave empleado por Cicerón en el De oratore para ilustrarnos sobre la justificación de tal principio está tomado de Platón ${ }^{148}$. Pero, a su vez, el divorcio entre ambos aspectos (utilitas y delectatio) era sostenido por determinadas corrientes filosóficas, como nos dice el propio Arpinate. Por ello las coincidencias en este terreno entre Cicerón y Horacio son más que accidentales. A este respecto debemos señalar, en primer lugar, que la quaestio entre utilitas y delectatio ofrecida por Cicerón es reproducida por Horacio con el carácter sentencioso que lo caracteriza: (AP 333) aut prodesse uolunt aut delectare poetae.

En segundo lugar, vemos cómo Horacio asume, al igual que el Arpinate, la integración de ambos aspectos, esto es, la conjunción de utilitas y delectatio: (AP 334) aut simul et iocunda et idonea dicere uitae. Así proclamará, algunos versos más adelante, de manera lapidaria:

AP 343-4: Omne tulit punctum qui miscuit utile dulci, lectorem delectando pariterque monendo.

${ }^{142}$ De fin. I 72: in quibus (poetis) nulla solida utilitas omnisque puerilis est delectatio.

${ }_{143}$ De or. II 21: nam et saeculis multis ante gymnasia inuenta sunt quam philosophi garrire coeperunt, et hoc tempore, quom omnia gymnasia philosophi teneant, tamen eroum auditores discum audire quam philosophum malunt, qui simul ut increpuit, in media oratione de maximis rebus et grauissimis disputantem philosophum omnes unctionis causa relinquont. Ita leuissimam delectationem grauissimae, ut ipsi ferunt, utilitati anteponunt.

144 Tusc. II, 8: Nam et Platonem reliquosque Socraticos et deinceps, eos qui ab his profecti sunt, legunt omnes, etiam qui illa aut non adprobant...

145 De fin. I 14: Sed existimo te, sicut nostrum Triarium, minus ab eo delectari, quod ista Platonis, Aristoteli, Theophrasti orationis ornamenta neglexerit.

146 Tusc. I 6: Sed mandare quemquam litteris cogitationes suas qui eas nec disponere nec illustrare possit nec delectatione aliqua allicere lectorem, hominis est intemperanter abutentis et otio et litteris.

147 Or. 62-3. H. Funke, "Zur Ars Poetica des Horaz", Hermes 104, 1976, pp. 191209: este autor pone en contacto con la Poética de Aristóteles tales principios (1460 a), puesto que en el Ion 533 e-534 b se rechazaba lo $\eta \delta$ có como objeto de la poesía.

${ }_{148}$ Gorg. 503 e. De or. III 180. 
Más aún, la sinonimia observada en la obra del Arpinate entre iucunditas y delectatio (De or. III 155) es recogida también por el Venusino (AP 333-4), así como la vinculación de tal delectatio con la uoluptas aurium (Or. 38; 58; 203, etc.; Ep. II 1,187).

Creemos, en consecuencia, que los principios horacianos del prodesse et delectare se vinculan preferentemente a los observados en el Arpinate.

Un hecho, por otra parte, bastante elocuente sobre tal asociación es la ecuación que observamos en Horacio entre los términos res y uerba. Tal ecuación conlleva un equilibrio armónico y, en consecuencia, la correspondiente exigencia hacia ambos aspectos. Así pues, el aspecto elocutivo no es, desde este punto de vista, una consecuencia natural del primer término (res), sino una exigencia que demanda su propia y específica atención. De ahi que Horacio reclame la debida consideración al ornamentum, según nos dice en $A P 440$ ss., o al limae labos (AP 291), invocando, incluso, para tal extremo la figura simbólica de Aristarco, tal como ya lo había hecho Cicerón (Pis. 75; Ep. I 14,3; IX 10,1; Att. I 14,3).

Evidentemente Horacio, al demandar el principio de la delectatio estaba enfrentándose con determinadas corrientes ideológicas y, en particular, con la estoica, como ya había hecho el Arpinate. Por ello, en lógica consecuencia, se suma a la crítica que Cicerón había realizado contra el lenguaje de éstos, llegando, incluso, a emplear los mismos atributos que aquél para descalificarlos. Así dirá de los versos que no atienden a tales demandas literarias que son inertis, incomptos, duros, asperos, agrestis, etc. ${ }^{149} \mathrm{Y}$, del mismo modo que Cicerón había descalificado la producción basada en afeites por afectación antinatural, Horacio desechará todo amaneramiento basado en el fucus ${ }^{150}$, buscando el color natural de la obra, como también lo había exigido el Arpinate.

149 AP 445-7: Vir bonus et prudens uersus reprehendet inertes

culpabit duros, incomptis allinet atrum

transuerso calamo signum.

Ep. I 18, 5-8: Est huic diuersum uitio uitium prope maius, asperitas agrestis et inconcinna grauisque...

M. T. Le Bon, "La uera uirtus chez Horace», Etudes horatiennes, Bruselas 1937, p. 146: «En esta Ep. I 18, 5-8 nos encontramos una crítica contra el estoicismo». Horacio ilustra magistralmente tal dureza y pesantez ofreciéndonos la secuencia de espondeos en Ars 456.

1so Sat. II 1, 60: Quisquis erit uitae scribam color.

Ars 85-6: Descriptas seruare uices operumque colores, cur ego, si nequeo ignoroque, poeta salutor?

Horacio asociará, asumiendo criterios estoicos, la uera uirtus con el color natural de la obra, libre de afeites o maquillajes desnaturalizadores: 
Horacio se enfrenta, pues, a los estoicos, asumiendo las mismas tesis que ellos, tal como ya lo había hecho Cicerón: aceptará el principio de la natura, como punto de referencia literaria, reclamando el principio del ornatus que la misma encierra.

Conviene, en este sentido, no confundir, como habitualmente se hace, el binomio utilitas / delectatio con el de utile / honestum o utile / iustum. Ya hemos señalado cómo Cicerón y Horacio consideraban necesario aunar los aspectos de la utilitas y delectatio para lograr una obra que instruyera y agradara a la vez, frente al criterio de los estoicos tan sólo interesados por el primer aspecto. El otro binomio (utile / honestum o iustum) aparecerá también recogido en la obra de ambos autores dentro de las tesis estoicas: Cicerón lo tratará ampliamente en el $D e$ officiis y Horacio en las Sátiras (I 3,98 ss.), género donde tales criterios estoicos tienen igualmente amplia acogida. Por lo tanto, si en este plano de la asociación de utile y honestum Cicerón y Horacio se adhieren a la tradición estoica, no ocurre lo mismo en el plano de la asociación de utilitas y delectatio, puesto que en este plano los estoicos rechazaban toda delectatio.

En definitiva, esta exigencia de la utilitas y delectatio es un trasunto de aquel otro binomio representado por sapientia / eloquentia, esto es, por res / uerba. Por lo tanto, si ya habíamos señalado el desafecto de los estoicos hacia el aspecto elocutivo, es lógico que tal desafecto se extendiera también a este principio de la delectatio, base precisamente del ornatus. Por otra parte, la argumentación empleada contra los estoicos así como la utilización de un lenguaje común hablan de la ascendencia de Cicerón sobre Horacio en este aspecto concreto.

\section{XiI. Atención al ornatrs}

$\mathrm{Si}$ en el terreno de los principios generales la opinión de ambos autores es concordante, lo mismo se puede decir con relación a aquellos otros aspectos más concretos de la producción literaria. Este es el caso del ornatus. Desde el momento en que Cicerón fija como objeto formal

\section{III 5, 27-30: ... Neque amissos colores lana refert medicata fuco, nec uera uirtus, cum semel excidit, curat reponi deterioribus.}

Evidentemente Horacio asumia criterios estoicos para rechazar las opiniones de aquéllos, como ya había hecho el Arpinate. Cf. A. Alberte, Cicerón ante la retórica, o.c., "Aspectos formales...". 
de los estudios retóricos el ornatus, se ve obligado a determinar dicho ornatus. Para ello utiliza dos coordenadas, la paradigmática (uerborum delectus) y la sintagmática (compositio o collocatio uerborum) ${ }^{151}$. La primera vía se basa en la selección del léxico, la segunda en la combinación del mismo:

De or. III 149: Est quidam ornatus orationis, qui ex singulis uerbis est, alius qui ex continuatis coniunctisque constat.

Or. 80: ornatus autem uerborum duplex: unus simplicium alter collocatorum.

En Horacio se observa claramente el seguimiento de tales criterios tanto en el Ars Poetica como en la Epistola a Floro ${ }^{152}$. Concretamente en el $\mathrm{Ars}$ podemos ver cómo Horacio hace referencia no sólo a la iunctura o series, esto es, al procedimiento sintagmático ( $A P$ 46-8; 242), sino también a la selección del vocabulario, esto es, al procedimiento paradigmático, señalando los mismos criterios para resolver las necesidades léxicas (Ars 48-53,70).

Así, en primer lugar, vemos cómo Horacio se inspira, incluso, en la argumentación ciceroniana para justificar la creación de nuevos términos, como se señala en el comentario de Orelli-Baiter ${ }^{153}$ :

De fin. 3,15: Si enim Zenoni licuit, cum rem aliquam inuenisset inusitatam, inauditum quoque ei rei nomen imponere, cur non liceat Catoni?

AP 53-5: ... quid autem

Caecilio Plautoque dabit Romanus adeptum

Vergilio Varioque?

151 A. Alberte, "La retórica moderna al trasluz de la retórica latina", EC 89, 1985, pp. 391-99.

152 Ep. II 2, 111 ss.: audebit quaecumque parum splendoris habebunt

et sine pondere erunt et honore indigna ferentur

uerba mouere loco, quamuis inuita recedant...

obscurata diu populo bonus eruet atque

proferet in lucem speciosa uocabula rerum...

adsciscet noua, quae genitor produxerit usus..

Orelli-Baiter, Horatius Flaccus, Berlin 1886 (repr. 1972), II, p. 576: «Iam (vv. 4659) dat praecepta de stili uirtutibus in uerborum dilectu, in iuncturis, in uerbis faciendis. Perquam similia sint, quae tradit Cicero (de orat. 3,149 )». J. H. Waszink, "Der dichterische Ausdruck in den Oden des Horaz", Wege der Forschung, IC, 1972, p. 282: «El texto que comienza con el v. 47 se abre con una consideración que afecta a la continuato uerborum». Ibidem, p. 283, n. 8: «Es evidente que Horacio había utilizado el famoso pasaje ciceroniano De or. III 149 ss.m. La interpretación de iunctura como una especie de la continuatio uerborum está avalada, en nuestra opinión, por el empleo que Quintiliano hace de este término en este sentido (IX 4, 17; 44), siendo Quintiliano precisamente un gran conocedor de la obra de Cicerón y Horacio.

${ }^{133}$ Orelli-Baiter, o.c., p. 578. Plessis-Lejay, o.e., n. 8: Se señala cómo la referencia a Caecilius hecha por Horacio (AP 55) ya habia sido realizada por Cicerón (Brut. 258. Att. VII 3, 10). 
Es evidente, en segundo lugar, la coincidencia de ambos autores en la apelación al uso moderado de arcaísmos, neologismos y préstamos griegos ${ }^{154}$, así como al imperativo de la necessitas para su empleo ${ }^{155}$.

En tercer lugar, conviene señalar que el criterio del usus o consuetudo, como referencia para el uso del lenguaje, es también común a uno y otro autor. En nuestro artículo «Cicerón y Quintiliano ante los principios analogistas y anomalistas» (Minerva 1, 1987, pp. 112-25) señalamos la oposición de las tesis ciceronianas a los planteamientos analogistas. Es, pues, indicativo de esta cognatio ideológica tal apelación al usus por parte de Horacio. En este sentido, frente a la opinión de M. Ruch ${ }^{156}$, quien consideraba que el concepto de usus en Horacio era distinto al que daban los tratados de retórica porque, en su opinión, el usus en Horacio tiene valor creativo, mientras que en los tratados retóricos era la bona consuetudo, un uso instalado en el pasado e incapaz de generar formas nuevas, nosotros nos remitimos a dicho artículo, donde se puede ver cómo el usus, según el Arpinate, es la uox populi, sujeta a las evoluciones y cambios propios de la lengua. Más aún, la preposición penes, cuya frecuencia de empleo es bajísima, aparece en dos textos referidos al concepto del usus, uno ciceroniano y otro horaciano, lo que traiciona tal dependencia de criterios ${ }^{157}$. En este orden de cosas, donde la coincidencia delata ya un furtum es en la expresión horaciana de medio sumptis ( $A P$ 243), tomada evidentemente de Or. 163 (uerba legenda sunt... sumpta de medio). Quintiliano, buen conocedor de la obra de ambos, la asumiría ya como un tecnicismo (V 7,31).

Por otra parte, dentro de este mismo terreno de la elocutio nos encontramos con el hecho de que Horacio asume los mismos criterios observados por Cicerón sobre los genera dicendi. Así, en primer lugar, se puede comprobar cómo el Venusino marcaba la diferencia entre sermo y poema sobre la base de la uis y la expresión literaria, como ya lo había hecho Cicerón. En efecto, el Arpinate trasladaba tal diferenciación a los términos sermo y contentio, apelando para ello a principios seme-

154 Horacio emplea los términos pudenter y parce para señalar la limitación al abuso renovador del lenguaje ( $A P$ 51-3 y $E p$. II 2,115$)$ al igual que se puede ver en el Arpinate. Cf. H. Funke, «Zur Ars poetica des Horaz», o.c., p. 192, n. 2.

155 Or. 211: necessitas cogat aut nouum facere uerbum aut a simili mutuari.

AP 48-9: ... si forte necesse est indiciis monstrare recentibus abdita rerum...

$156 \mathrm{M}$. Ruch, «Horace et les fondaments de la iunctura dans l'ordre de la création poétique», $R E L 41,1963,246-9$.

157 AP 71-2: ... quem si uolet usus, quem penes arbitrium est et ius et norma loquendi.

Ep. II 2, 119. Brut. 258: fundamentum orationis, locutionem emendatam et Latinam cuius penes quos fuit laus... 
jantes: (De off. II 48) Sed cum duplex ratio sit orationis, quarum in altera sermo sit, in altera contentio, non est id quidem dubium, quin contentio orationis maiorem habeat uim. Cf. De off. I 132. Desde este punto de vista el Arpinate adscribía el estilo socrático al sermo: (De off. I 134) Sit ergo hic sermo in quo maxime Socratici excellunt.

Parecida oposición será la establecida por el Arpinate en sus tratados retóricos entre sermo y oratio, si bien en este caso la marca estaba fijada más en aspectos formales que de tensión (Or. 64 y 113-4; De or. III 53). Del mismo modo Cicerón adscribe en estos tratados el estilo socrático al nivel del sermo y no de la oratio: (De or. III 62) in Socratico sermone.

Ahora bien, no sólo llama la atención el que en ambos autores hayan sido observados criterios comunes sobre la oposición, por un lado de sermo y contentio u oratio y, por otro, de sermo y poema, sino el que en ambos autores se haya adscrito el estilo socrático a la categoría del sermo. Concretamente Horacio utilizará la misma fórmula que habíamos visto en Cicerón para referirse a dicho estilo socrático:

\section{III 21,9-10: ... quamquam Socraticis madet sermonibus.}

Por otra parte, Cicerón, al hablar de la oratio, distinguía los tres genera dicendi (summisus, medius, sublimis). Tal distinción constituye precisamente el eje del Orator. Pues bien, una definición así no la hallamos en Horacio, circunstancia ésta que habria de motivar el que algunos filólogos señalaran el desconocimiento por los poetas augústeos de estos tres estilos o genera dicendi ${ }^{158}$. Ahora bien, el hecho de que Horacio no haga mención expresa de estos tres estilos no quiere decir que los haya desconocido o ignorado. Todo lo contrario. $\mathrm{Si}$ recordamos, en primer lugar, las notae et formulae (Or. 75) con las que el Arpinate define cada uno de estos tres estilos; si tenemos en cuenta, en segundo lugar, la relación establecida en el Orator entre los distintos estilos o genera dicendi y las funciones del orador (officia oratoris), y si, por último, no nos olvidamos de los símiles que el Arpinate había utilizado para ilustrar la naturaleza de cada uno de tales estilos, nos daremos cuenta no sólo de la plasmación de estos genera dicendi en la obra del Venusino sino también de la influencia del Arpinate sobre Horacio. En efecto, observando

158 A. Fontán, "Tenuis Musa?...», o.c., p. 205: «No he encontrado, en efecto, ningún testimonio explícito de la aceptación por los poetas augústeos de un tertius o mediocris character. Ellos contraponen con frecuencia solamente dos especies de poemas que define Horacio con las palabras tenues y grandian. 
con atención los siguientes versos del Ars Poetica se llega a reconocer aquella triple división de estilos, ampliamente desarrollada por el Arpinate:

AP 99-100: Non satis est pulchra esse poemata, dulcia sunto et, quocumque uolent, animum auditoris agunto.

En primer lugar se puede comprobar que la caracterización hecha por Cicerón sobre el estilo humilde e intermedio ha sido reproducida por Horacio a través de los atributos pulchra y dulcia, correlativamente. En efecto, del estilo humilde Cicerón exigía como premisas básicas aquellas uirtutes dicendi, propias de la latinitas tales como la emendatio y la pulchritudo o munditia, desde el momento en que los demás principios estilísticos propios del ornatus le estaban permitidos tan sólo a un nivel muy reducido. Por ello Horacio, al emplear el término pulchra, estaba haciendo referencia a este estilo humilde ${ }^{159}$. De igual manera, al caracterizar Cicerón el estilo intermedio (medium, temperatum), destacaba como rasgo distintivo del mismo su dulzura: (Or. 94) Haec frequentat Phalerius maxime suntque dulcissima. Dicho atributo, recogido también por Horacio, está consiguientemente haciendo referencia a este estilo intermedio.

En segundo lugar, conviene recordar la asociación establecida por el Arpinate entre el estilo elevado y la función del mouere animos: (Or. 69) Sed quot officia oratoris, tot sunt genera dicendi: subtile in probando, modicum in delectando, uehemens in flectendo. Cf. Or. 20. Dicha asociación permite, pues, referirse al estilo elevado a través de la función del mouere animos y esto es lo que hace Horacio en $A P 101$.

Incluso la exigencia señalada por Horacio sobre la necesidad de no limitarse al genus humile ( $A P$ 100: Non satis est pulchra esse poemata) es la misma que expresa Cicerón al exigir del orador el dominio de todos los niveles estilisticos, como reproche contra los aticistas, limitados tan sólo al Latine loqui: (De or. III 52) Nemo enim umquam est oratorem, quod Latine loqueretur, admiratus. Evidentemente Cicerón interpretaba negativamente la actitud estilística de los aticistas, al señalar que el hablar correctamente no es suficiente desde el punto de vista oratorio $(O r$. 28). Esta misma idea es la que nos había sido transmitida a través de los tratados retóricos en los que no sólo se daban normas para evitar errores sino también para alcanzar objetivos literarios. Un eco de tales

159 Or. 79: elegantia modo et munditia remanebit, sermo purus erit et Latinus dilucide planeque dicetur... 
exigencias es la sentencia horaciana: (AP 267-8) uitaui denique culpam / non laudem merui.

En tercer lugar se puede detectar fácilmente cómo la alusión hecha por Horacio ( $A P$ 28) sobre la seguridad en que se desenvuelve el estilo humilde, por hallarse apegado al suelo y no arriesgar nada, se corresponde con aquella misma caracterización observada en Cicerón sobre la seguridad de dicho estilo: (Or. 98) minimeque in lubrico uersabitur et, si semel constiterit, numquam cadet.

La influencia del Arpinate sobre Horacio en esta materia es tal que el Venusino reproduce poéticamente la definición de estilo sencillo dada por el Arpinate en el Orator, si bien tales características las proyecta sobre el poema de tema común ${ }^{160}$ :

Or. 76: Summissus est et humilis, consuetudinem imitans, ab indisertis re plus quam opinione differens. Itaque cum qui audiunt quamuis ipsi infantes sint, tamen illo modo confidunt se posse dicere. Nam orationis subtilitas imitabilis illa quidem uidetur esse existimanti, sed nihil est experienti minus.

$A P$ 240-3: Ex noto fictum carmen sequar, ut sibi quiuis speret idem, sudet multum frustraque laboret ausus idem.

El paralelismo de ambas construcciones es, pues, evidente. En primer lugar, la expresión ciceroniana consuetudinem imitans está recogida por la expresión horaciana ex noto. En segundo lugar, el desarrollo ciceroniano qui audiunt quamuis ipsi infantes sint se corresponde al quiuis horaciano. En tercer lugar, la expresión illo modo confidunt se posse dicere se corresponde a la fórmula horaciana speret idem. En cuarto lugar, la sentencia ciceroniana nam orationis subtilitas... experienti minus está recogida por la frase horaciana sudet... ausus idem.

Evidentemente mientras Cicerón desarrolla de manera amplificada este concepto del estilo sencillo, Horacio lo sintetiza poéticamente, manteniendo la misma secuencia expositiva.

Es, pues, evidente que al trasluz de los textos ciceronianos se reconoce la triple división de los genera dicendi en la obra de Horacio, aun cuando no haga mención explícita de ello, llegando a alcanzar esta influencia ciceroniana al empleo de un mismo vocabulario ${ }^{161}$.

160 Grant-Fiske, "Cicero's orator...», o.c., ponen en relación tales pasajes. Vemos, por otra parte, que Horacio repite la misma idea en Ep. II 1, 168.

161 Grant-Fiske, "Cicero's orator...», p. 43: se señala la correspondencia terminológica entre estos dos autores a la hora de calificar cada uno de los tres estilos. Cf. H. Funke, o.c., p. 192, n. 2: "Tenuis auctor se remonta a Cicerón, Or. 81, tenuis oratorn. 
Desde esta asunción de criterios ciceronianos por parte del Venusino encuentra su justificación el principio de la uariatio ampliamente desarrollado en el Orator y apuntado también en el Ars Poetica. Cicerón señalaba, tras exigir del orador el dominio de todos los estilos, la necesidad de que supiera conjugarlos debidamente para evitar la redundancia o bien la inadecuación con el asunto. Consiguientemente el Arpinate exponía tal principio después de haber tratado sobre cada uno de los genera dicendi. Pues bien, esta misma situación es la observada en Horacio. Este autor hace mención a la misma tras haberse referido a cada uno de los estilos literarios:

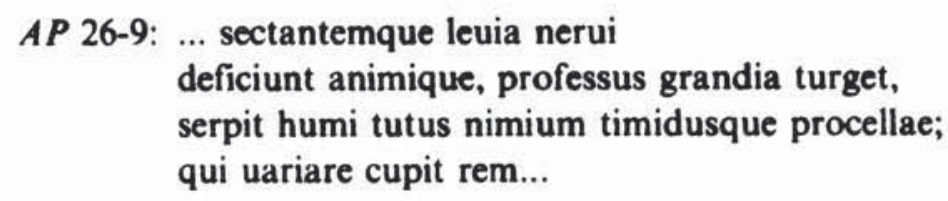

Incluso la visión evolutiva de las artes y ciencias que vemos desarrollada ampliamente en el Brutus y Orator ciceronianos encuentra clara correspondencia en Horacio, quien basaba la calidad literaria de una obra no en su antigüedad, como hacían los aticistas, según Cicerón, sino en su valor perfectible con el tiempo. Y así como Cicerón se consideraba superior a las generaciones que le habían precedido, así también Horacio se consideraba superior a Lucilio en este proceso de perfeccionamiento histórico, como lo manifiesta en Sat. I 1: así como Lucilio corrige a Ennio y Accio (53-5), así también él puede considerarse en ventaja frente a Lucilio (56 ss.). De ahí que llegue a decir de éste que si le hubiera tocado en suerte vivir en su época habría corregido muchos de sus errores (67-71). De igual modo en Ep. II 1,64 ss. critica también a quienes anteponian la poesía arcaica por ser tal sin reparar en la evolución y perfeccionamiento histórico.

En conclusión vemos cómo la teoría ciceroniana del ornatus fue plenamente asumida por Horacio.

\section{NECESIDAD DE LA DOCTRINA GRIEGA}

Si en ambos autores observamos unanimidad sobre principios estéticos es lógico que la misma se extienda a la valoración que hacen sobre la cultura griega desde el momento en que ambos no sólo eran conscientes de su influencia sino también deudores de la misma.

La actitud de Cicerón ante dicha cultura se manifiesta claramente al comienzo de las Tusculanas: alli se exaltan las virtudes naturales de los 
romanos frente a la superioridad cultural de los griegos y se considera que dichas virtudes pueden plenificarse si son fecundadas con la doctrina y cultura griegas ${ }^{162}$. Así pues, Cicerón, a pesar de ciertas afirmaciones patrióticas ${ }^{163}$, no dejará de reconocer este hecho de la superioridad cultural griega y de la necesidad de su asunción ${ }^{164}$.

Esta misma actitud es la que observamos en Horacio. Si bien reconoce la superioridad cultural griega ${ }^{165}$, reclama para el romano la superioridad de virtudes y espíritu militar ${ }^{166}$. De ahí que el Venusino invoque también la necesidad de buscar modelos literarios en el mundo griego ${ }^{167}$, sin caer en el extremismo de ignorar la propia lengua ${ }^{168}$.

Tal identificación de criterios sobre este punto se hace manifiesta en la utilización que Horacio hace de una imagen ciceroniana en la que se exalta el mundo de la cultura griega frente al espíritu materialista romano:

(Tusc. I 5) In summo apud illos honore geometria fuit, itaque nihil mathematicis inlustrius; at nos metiendi ratiocinandique utilitate huius artis terminauimus modum.

$A P$ 323-6: Grais ingenium, Grais dedit ore rotundo musa loqui, praeter laudem nullius auaris; Romani pueri longis rationibus assem discunt in partes...

Más aún, la famosa sentencia horaciana (Ep. II 1, 56-7) Graecia capta ferum uictorem cepit et artes / intulit agresti Latio parece inspirarse en aquella otra que leemos en Brut. 254: Quo enim uno uincebamur a uicta Graecia, id aut ereptum illis est aut certe nobiscum communicatum. Aquí,

${ }^{162}$ Tusc. I 1-2. De or. II 2-3; II 55; II 152; III 75; III 137. De off. I 1. Flac. 9.

${ }^{163}$ De fin. I 10; III 51.

164 Or. 23. Fr. Wehrli, «Studien zu Cicero de oratore», $M H$ 35, 1978, p. 78: «Para Cicerón la helenización no supuso ni mucho menos la ruptura de una representación de valores tradicionales, sino la posibilidad de afirmar conceptualmente aquéllos». U. Knoche, "Cicero, ein Mittler griechischer Geisteskultur", Hermes 87, 1959, p. 57: el autor señala la intención de Cicerón de fundir la uirtus romana con la cultura griega para generar una nueva paideia.

${ }_{165}$ Ep. II 1, 28-31; II 1, 124; II 1, 165; II 2, 7.

166 AP 289-90. L. Bösing, o.c., p. 11: «Según Fränkel la opinión de Horacio sobre la poesía griega sería: la poesía griega en su conjunto sería el producto de un género de vida afeminado e inmoral. La vida primitiva romana sería, en cambio, algo digno pero ajeno al arte poético. Pero sería posible unir las cualidades morales y políticas del pueblo romano y los dones de la musa griega». H. Funke, o.c., señala también el marcado contraste entre la uirtus y las armas romanas, por un lado, y el ars y doctrina griega por otro.

167 AP 268. Ep. II 2, 43.

168 Sat. I 10, 15 y 31 . 
como en ocasiones anteriores, la formulación ciceroniana es condensada por Horacio pero manteniendo el oxímoro retórico ${ }^{169}$.

Horacio se integraba, pues, en aquella misma corriente ciceroniana de fundir la uirtus romana con la doctrina griega. En consecuencia, a la hora de caracterizar a aquellos personajes más sobresalientes de la historia de Roma, Horacio asumirá prácticamente la misma valoración observada en Cicerón.

En efecto, el Arpinate definía los discursos de Catón el Censor como orationes horridulae, caracterización que habia asumido también Horacio, como ya hemos comentado ${ }^{170}$. De igual modo, si de Escipión Emiliano Horacio destacaba aquellas notas propias de la exigencia estoica, tales como sapiens et fortis, reflejadas, por otra parte, en los sepulcros de esta familia ${ }^{171}$, de Lelio destacará aquel rasgo que se refleja en la obra del Arpinate, la suavidad y dulzura ${ }^{172}$. Incluso la calificación que hace de Ennio como alter Homerus (Ep. II 1,50) parece fundamentarse en el comentario que Cicerón nos ofrece en $A c$. II 51.

Un hecho revelador de esta ascendencia ciceroniana sobre Horacio es la transmisión por parte del Venusino de aquella escena tierna y familiar que leemos en Cicerón sobre el solazamiento de estos dos hombres, Escipión y Lelio, una vez liberados de compromisos y obligaciones sociales:

De or. II 22: Saepe ex socero meo audiui, cum is diceret socerum suum Laelium semper cum Scipione solitum rusticari eosque incredibiliter repuerascere esse solitos, cum rus ex urbe tamquam ex uinculis euoluissent.

Sat. II 1,71-4: Quin ubi se a uolgo et scaena in secreta remorant uirtus Scipiadae et mitis sapientia Laeli, nugari cum illo et discincti ludere, donec decoqueretur holus, soliti.

L. Bösing, por su parte, considera que la escena de la Roma patriarcal descrita por Horacio en la Epistola a Augusto (93-102) está basada

169 "Graecia capta ferum uictorem cepit», ASNP, 1978, pp. 1007-24. Según este autor, en $E p$. II 1, 156-7, se esconde una refinada alusión a la conquista de Corinto (146 a.C.) por el cónsul L. Mumio (Achaia capta) y a la realidad contemporánea de Augusto celebrada en sus Res gestae Diui Augusti triumphales.

${ }_{170}$ Cf. n. 82.

171 Tusc. I 7, 13. A. Ernout, Recueil de Textes Latins archaiques, París 1957, p. 12. A Grilli, "Orazio e l'epicureismo (ovvero Serm. I, 3 y Epist. I, 12)", Helmantica 103-5, 1983, p. 270: «Horacio exhorta al uir fortis et sapiens como en los Elogia Scipionum».

172 Sat. II 1, 72: mitis... Laeli. Brut. 295. Lael. 66. 
en un cuadro semejante ofrecido por el Arpinate en De or. I 199 y De leg. I 10.

Conviene recordar, al respecto, que los exempla romanos mostrados por Horacio están igualmente inspirados en aquellos mismos que Cicerón habia of recido anteriormente, como señala V. Bejarano ${ }^{173}$.

Esta misma coincidencia de criterios se evidencia en la valoración hecha por ambos sobre el beneficio de la cultura griega sin menoscabar la propia naturaleza y personalidad romana. En efecto, la lapidaria recomendación horaciana (AP 268-9) uos exemplaria Graeca nocturna uersate manu / uersate diurna se inscribe en el marco de aquellas exigencias educativas observadas en el De oratore ${ }^{174}$, donde se fija como programa de actividades para el futuro orador el estudio, comentario y adaptación de textos griegos.

Desde tal requerimiento de la doctrina griega para un mayor desarrollo de la propia lengua y cultura latinas se comprende el comportamiento unísono de Cicerón y Horacio en la renuncia a realizar su a:tividad literaria en griego, a pesar del profundo dominio que amoos autores tenían de esta lengua ${ }^{175}$. Precisamente tal enriquecimiento habría de traducirse para estos dos autores no en una helenización de su propia lengua con su consiguiente desnaturalización sino en el desarrollo de sus propios recursos lingüísticos por la vía del calco. De este modo ambos autores estaban salvaguardando aquel principio básico del Latine loqui ${ }^{176}$. Dentro de este mismo propósito se halla aquella interpretación concordante en ambos autores sobre la libertad recreadora

${ }^{173}$ V. Bejarano, «Poesía y política en Horacio», EC 78, 1976, pp. 240-84: «Esta Oda (I 12) contiene una serie de exempla... Régulo es aquel de quien Cicerón señalaba la Atiliana uirtus... Los otros tres romanos son ejemplo de pobreza y austeridad y ya habían sido agrupados por Cicerón como modelos de frugalidad antigua (Pro Caelio 39)".

174 De or. I 155: Postea mihi placuit, eoque sum usus adulescens, ut summorum oratorum Graecas orationes explicarem, quibus lectis hoc adsequebatur, ut cum ea, quae legeram Graece, Latine redderem, non solum optimis uerbis uterer et tamen usitatis, sed etiam exprimerem quaedam imitando, quae noua nostris essent, dum modo essent idonea.

175 De fin. I 1: Non eram nescius, Brute, cum, quae summi exquisitaque doctrina philosophi Graeco sermone tractauissent, ea Latinis litteris mandaremus, fore ut hic noster labor in uarias reprehensiones incurreret.

Sat. I 10, 31-2: Atque ego cum Graecos facerem, natus mare citra, uersiculos, uetuit me tali uoce Quirinus...

H. I. Marrou, Historia de la Educación en la Antigüedad (trad. cast. de la 3." ed. de la Histoire de l'Education dans l'Antiquité, París 1955), Buenos Aires 1970, p. 311 ss.

176 Cf. n. 174.

C. 53-4: Et noua fictaque nuper habebunt uerba fidem si

Graeco fonte cadunt parce detorta. 
que debe presidir la tarea de trasladar textos griegos al latín, evitando, de este modo, la imitación servil del seruum pecus ${ }^{177}$.

En conclusión, Horacio se adhiere, una vez más, a los criterios del Arpinate sobre la necesidad de conocer las fuentes griegas para fecundar que no desnaturalizar aquellos mores maiorum, caracterizados por los principios éticos.

\section{ConClusión}

Tras haber observado la amplia resonancia que los criterios estéticoliterarios de Cicerón tuvieron en la obra de Horacio, surge la inevitable pregunta: ¿por qué Horacio no citó a Cicerón?

No tiene sentido pensar en la omisión del nombre para evitar la sospecha de tal deuda cuando el propio Horacio reconocía en su Ars Poetica el mérito que tenía toda reelaboración literaria bien hecha y cuando él mismo cita en sus Odas, obra de la que se siente especialmente orgulloso, a los poetas griegos que le habían servido de modelo ${ }^{178}$. Tampoco es posible pensar en la "impertinencia» de la mención de un orador en temas poéticos cuando los exempla y syncrisis que nos ofrece presentaban no sólo figuras ilustres de la historia romana pasada sino también personajes contemporáneos y oradores romanos. ¿Cómo es posible que ignorara no sólo al princeps libertatis, encarnación de la República, sino también al princeps eloquentiae? ${ }^{179}$

«Cuando Cicerón es asesinado Horacio tenía 22 años, estaba en contacto con la vida literaria» ${ }^{180}$. Más aún, su condición originariamente republicana, su presencia en Atenas coincidente con la de Marco, hijo de Cicerón, su vinculación al ejército de Bruto, el gran número de amigos comunes, etc., hacen suponer que la personalidad histórica del Arpinate no podia ser indiferente para Horacio ${ }^{181}$. Su silencio es, pues,

Sat. I 10, 27-30: Scilicet oblitus patriaeque patrisque Latini, cum Pedius causas exsudet Poplicola atque Coruinus, patriis intermiscere petita uerba foris malis, Canusini more bilinguis?

177 AP 133-4: Nec uerbo uerbum curabis reddere fidus interpres...

De opt. gen. or. 14: Nec conuerti ut interpres, sed ut orator.

178 Schanz-Hosius, Geschichte der römischen Literatur, Munich 1935, II, p. 143.

179 Parad. 30: et me tuo nomine appellas, cum omnes meo discessu exsulasse rem publicam putent?

180 A. Fontán, "Cicerón y Horacio, críticos literarios», o.c., p. 196.

181 B. Stenuit, "Le séjour d'Horace à Athènes», LEC 47, 1974, pp. 249-55.

S. Treggiari, "Cicero, Horace and mutual friends", Phoenix 27, 1973, pp. 245-61.

E. Fränkel, Horace, Oxford, 1957, p. 8. Plut., Cic. 45. 
un silencio muy significativo, tratándose de un hombre que, como él mismo decía en frase de cuño ciceroniano, no se sentía comprometido con ninguna escuela filosófica y procuraba, por otra parte, conservar siempre su independencia ${ }^{182}$. La clave de tal silencio nos la ofrece, entre otros, Séneca el rétor y Veleyo Patérculo, como señala W. Richter ${ }^{183}$. En efecto, según se desprende de la lectura de estos autores la memoria de Cicerón había sufrido en época de Augusto la consiguiente proscripción. Concretamente un pasaje de Plutarco ${ }^{184}$, en el que se nos relata cómo un sobrino de Augusto ante la inesperada presencia de éste esconde ruborizadamente un libro de Cicerón que estaba leyendo, revela claramente el temor que infundía cualquier alusión hacia este hombre. En este sentido use ha destacado que ninguno de los grandes poetas de esta época hablara de Cicerón» ${ }^{185}$, lo que confirma el carácter tabú que su nombre entrañaba en el círculo de las amistades de Augusto. Evidentemente la cita del gran defensor republicano tenía que resultar provocativa para quien había sido corresponsable de su muerte ${ }^{186}$, máxime tratándose de un hombre que le había llamado padre ${ }^{187}$. Más aún, por el comentario de Suetonio sobre las recriminaciones veladas de Augusto a Horacio, podemos deducir el riesgo que supondría para este antiguo republicano la cita de Cicerón ${ }^{188}$. Tendrían que pasar varios años para que la laudatio Ciceronis que nos presenta Plinio el Viejo ya no fuera una temeridad ${ }^{189}$. Así pues, aun cuando el pensamiento doctrinario de Cicerón hubiera inspirado la acción de gobierno de Augusto ${ }^{190}$, su nombre, por las connotaciones que evocaba, permanecía proscrito. No es, por tanto, extraño que el Venusino asumiera las tesis estético-literarias de aquél sin poder mentar su nombre.

Antonio Alberte

${ }^{182}$ E. Bréguet, «Horace, un homme libre», Homm. à M. Niedermann, París 1956, pp. 82-9.

${ }^{183}$ W. Richter, Cicero, ein Mensch seiner Zeit, Berlin 1968, pp. 161-2. Sen., Contr. I, praef. Vell. Pat., II 34 y 65.

184 Plut., Cic. 49.

185 G. Boissier, Cicéron et ses amis, París 1923, pp. 412-3.

186 Plut., Cic. 42.

187 Ad Brut. I 17, 5: licet ergo patrem appellet Octauius Ciceronem. Plut., Cic. 45. M. Bellincioni, Cicero politico nell'ultimo anno di vita, Brescia 1974, p. 274. H. Eulenberg, Cicero, Berlín 1932, p. 199: «Octavio intentó más tarde como Augustus reparar en su hijo la culpa cometida contra el padre».

iss Suet., Poet. 40.

189 W. Richter, o.c., p. 161.

190 E. Ciaceri, Cicerone e $i$ suoi tempi, Roma 1930, pp. 373-4. 